\title{
2 \\ General Determinants of Financial Development
}

\subsection{Introduction}

This chapter attempts to examine systematically the factors that might account for cross-country differences in financial development. It employs two modern quantitative methods, Bayesian Model Averaging (BMA) and General-to-specific (Gets) approaches, to gauge the robustness of a selection of possible determinants of financial development. Special emphasis has been placed on the contributions that institutions, policy and geography may have in developing financial markets.

First, we take a look at some simple contrasts in the financial development experience. The United Kingdom and France have similar levels of GDP per capita, democratic institutions and geographic characteristics in terms of latitude, access to the sea and distance from large markets. Nevertheless, they follow different legal traditions, reflected in different legal practices towards the protection of private property rights. In the 1990s, stock market capitalization to GDP ratio in the UK was more than three times higher than that in France, while the ratio of private credit to GDP in the UK (112\%) was noticeably higher than the same ratio in France $(89 \%)$. How much of the difference in financial depth between the UK and France is due to the difference in their legal traditions and practices?

The financial development experience in Latin American countries provides an enlightening example of the possible role of macroeconomic policies in financial development given the similarities of geographic conditions, institutional development and cultural characteristics. After implementing market-oriented policies in the 1970s and establishing prudential regulations in the 1980s, Chile achieved remarkable growth in financial intermediary development and stock market capitalization, 
and has been regarded as the financial leader in Latin America since the mid-1980s. In the 1990s both the ratio of liquid liabilities to GDP and the ratio of private credit to GDP in Chile were 50 percentage points higher than those of Brazil, the second best country in the region. Stock market capitalization as a fraction of GDP in Chile in the 1990s was 78\%, at least three times larger than that in any other Latin American country. How much of the success of Chilean financial development is due to better macroeconomic policies?

In the 1990s the ratio of credit issued to the private sector to GDP in Canada was 94\%, more than four times higher than that in Mexico of 23\%. Stock market capitalization as a fraction of GDP in Canada in 1990s was 65\%, more than twice as high as in Mexico (31\%). Canada and Mexico share a number of similarities in terms of geographic endowments and institutional development. More specifically, both of them have access to the sea, have a long border with the biggest developed country, have a large land area and a democratic political system, etc. However, among other factors, Canada and Mexico apparently differ in income level and latitude, which is associated with historical dominance of tropical cash crops in Mexico and grain in Canada. How much of the difference in financial depth between Canada and Mexico is due to the difference in income level and how much is due to their geographic endowment, and its long-run effects on institutions?

Exploring what determines financial development has become an increasingly significant research topic in recent years. Examples are La Porta et al. (1997, 1998), Beck et al. (2003), Rajan and Zingales (2003) and Stulz and Williamson (2003) to mention a few. La Porta et al. (1997, 1998) have made a significant contribution to this topic with regard to the legal determinants of financial development. By applying the settler mortality hypothesis of Acemoglu et al. (2001) to financial development, Beck et al. (2003) address how institutions matter for financial development. The Rajan and Zingales (2003) interest groups theory argues that politics matter for financial development. Stulz and Williamson (2003) illustrate that culture matters, although it may be tempered by openness. As to the role of policy, among others, Baltagi et al. (2009) study the importance of trade openness, whilst Chinn and Ito (2006) focus on the effect of financial openness.

Besides this, there is a large body of research aiming to identify the determinants of financial development, ranging from some emphasizing macroeconomic factors such as inflation, the income level (in terms of GDP per capita) and the saving rate to others stressing institutional and geographic factors. Since the relevant economic theories provide limited 
guidance on the specification of a cross-country regression for financial development, it is not clear which of these factors, acting relatively independently, plays the primary role in determining financial development when they are all taken into consideration. Formally speaking, there is a model uncertainty problem concerning which variables should be included in the model to capture the underlying data-generating process.

When facing a situation where a vast literature suggests a variety of economic policy, political and institutional factors as determinants of long-run average growth rates, Levine and Renelt (1992) raised a concern over the robustness of existing conclusions in cross-section growth regressions. They found that only a few variables can be regarded as robust determinants of growth and almost all results are "fragile". They suggested applying a version of "extreme bounds analysis" to the problem of model uncertainty. Motivated by this influential work, Salai-Martin (1997a, 1997b), Fernandez et al. (2001) and Sala-i-Martin et al. (2004) are significant works among others that have investigated the contributions of various factors to cross-country growth. These works have emphasized the Bayesian method as a potential technique for addressing model uncertainty.

Empirical research on the determinants of financial development encounters a similar model uncertainty problem to that on economic growth. This chapter is the first attempt to study extensively the structural determinants of financial development using a large array of variables, by jointly applying BMA and the so-called LSE Gets approach, which is another modern method aiming to recover the true datagenerating process. The Gets method has been recently developed and advocated by David Hendry and other practitioners (Hoover and Perez, 1999; Krolzig and Hendry, 2001 and Hendry and Krolzig, 2005 for example). To date, BMA and Gets have become more and more popular for the purpose of model selection, although the theory of econometric model selection is still underdeveloped.

Not only will this chapter look at each individual factor, but it also pays special attention to the roles of institutions, policy and geography in the process of financial development. ${ }^{2}$ There has been substantial research on the role of institutions, policies and geography in the process of economic development in which much work regards institutions as the fundamental factor in long-run growth (Acemoglu et al., 2001; Dollar and Kraay, 2003; Easterly and Levine, 2003 and Rodrik et al., 2004). In particular, research by Easterly and Levine (2003) and Rodrik et al. (2004) highlights the dominant role of institutions over those 
of geography and policy. They argue that geography and policy affect economic development through institutions by influencing institutional quality, and the direct effect of geography and policy on development becomes weaker once institutions are controlled for. Is this also the case for financial development?

In three aspects, this chapter exhibits distinct innovations and strengths. First, it considers a wider assortment of economic, political and geographic variables than any previous study. The second aspect is its joint application of the BMA and Gets procedures, which combines the strengths of each method. By jointly applying two modern methods using a wide range of variables, more reliable conclusions can be expected. Third, since, as pointed out by Levine (2005), there is no uniformly accepted proxy for financial development currently available, this paper constructs a composite index of financial development using principal component analysis, which enables us to look at different dimensions of financial development including overall financial development, financial intermediary development, stock market development, financial efficiency development and financial size development (usually called "financial depth").

The analyses based on the BMA and Gets procedures lead to the following findings. Institutions, macroeconomic policies and geography, when taken as groups, together with cultural characteristics and the income level of a country, are significantly associated with the level of financial development. Of 39 variables taken individually, legal origins, a government quality index, a trade policy index, land area, initial GDP, initial population and the population fraction of speakers of the main Western languages are found to be important determinants of financial development. In particular, this research highlights the dominant roles played by initial GDP, legal origin and institutional quality in the process of financial development.

The following section includes a description of the data. Section 2.3 discusses the empirical strategy and is followed by the empirical results of both BMA and Gets in Section 2.4. Section 2.5 summarizes the conclusions.

\subsection{The data}

This section describes the sample of countries on which this study is undertaken, and the measures of financial development and potential determinants. Appendix Table A2.1 contains the description and sources of these variables and Appendix Table A2.2 presents summary statistics. 


\subsubsection{Samples}

This study mainly investigates key determinants of five specific indices of financial development discussed in more depth below. For each financial index, there are three samples on which the investigation is based: the whole sample, a developing country sample and a smaller sample for which the La Porta et al. (1998) data are available. The whole sample is the main focus of the analysis. The developing countries in the settler mortality dataset of Acemoglu et al. (2001) form the main part of the developing country sample here. Looking at the smaller La Porta et al. (1998) sample makes it possible to examine whether differences in legal tradition, reflected in the protection of shareholders' and creditors' rights, determine cross-country differences in financial development. The countries included are listed in Appendix Table A2.3.

Note that the transition economies and small economies with a population of less than 500,000 in 1990 are excluded from the sample. The information on the transition economies and population size is from the World Bank Global Development Network Database (GDN) and the Penn World Table 6.2 from Heston et al. (2006), respectively.

\subsubsection{Measures of financial development}

Since there is no single aggregate index for financial development in the literature, we use principal component analysis based on widely used indicators of financial development to produce new aggregate indices.

Essentially the principal components analysis takes $N$ specific indicators and produces new indices (the principal components) $\mathrm{X}_{1}, \mathrm{X}_{2}, \ldots \mathrm{X}_{N}$ that are mutually uncorrelated. Each principal component, as a linear combination of the $N$ indicators, captures a different dimension of the data. Typically the variances of several of the principal components are low enough to be negligible, and hence the majority of the variation in the data will then be captured by a small number of indices. This chapter uses the first principal component, which accounts for the greatest amount of the variation in the original set of indicators, in the sense that the linear combination corresponding to the first principal component has the highest sample variance, subject to the constraint that the sum-of-squares of the weights placed on the (standardized) indicators is equal to one.

The conventional measures of financial development on which the principal component analysis is based are as follows. ${ }^{3}$

The first measure, Liquid Liabilities $(L L Y)$, is one of the major indicators used to measure the size, relative to the economy, of financial 
intermediaries, including three types of financial institutions: the central bank, deposit money banks and other financial institutions. It is calculated as the liquid liabilities of banks and non-bank financial intermediaries (currency plus demand and interest-bearing liabilities) over GDP.

The second indicator, Private Credit (PRIVO), is defined as the credit issued to the private sector by banks and other financial intermediaries divided by GDP, excluding credit issued to government, government agencies and public enterprises, as well as the credit issued by the monetary authority and development banks. It measures general financial intermediary activities provided to the private sector.

The third, Commercial-Central Bank (BTOT), is the ratio of commercial bank assets to the sum of commercial bank and central bank assets. It proxies the advantage of financial intermediaries in channelling savings to investment, monitoring firms, influencing corporate governance and undertaking risk management relative to the central bank.

Next are two efficiency measures for the banking sector. Overhead Costs $(O V C)$ is the ratio of overhead costs to total bank assets. The Net Interest Margin (NIM) equals the difference between bank interest income and interest expenses, divided by total assets. A lower value of overhead costs and net interest margin is frequently interpreted as indicating greater competition and efficiency.

The last are three indices for stock market development. ${ }^{4}$ Stock Market Capitalization $(M C A P)$, the size index, is the ratio of the value of listed domestic shares to GDP. Total Value Traded (TVT), as an indicator to measure market activity, is the ratio of the value of domestic shares traded on domestic exchanges to GDP, and can be used to gauge market liquidity on an economy-wide basis. Turnover Ratio (TOR) is the ratio of the value of domestic share transactions on domestic exchanges to the total value of listed domestic shares. A high value of the turnover ratio will indicate a more liquid (and potentially more efficient) equity market.

The data are obtained from the World Bank's Financial Structure and Economic Development Database (2008) and averaged over 1990-2001. Any country for which fewer than three years of data are available is omitted from the sample.

Appendix Table A2.4 presents the eigenvalues, proportion explained and the eigenvector of each first principal component from which the new indices of financial development are defined. It reports the sample variance of each first principal component (linear combination), the proportion of the variance in the raw data the first principal component accounts for and the coefficient (weight) of each existing standardized measure in the linear combination. 
(1) The first is a measure of overall financial development, denoted by FD. This is based on eight components, namely Liquid Liabilities, Private Credit, Commercial-central Bank, Overhead Cost, Net Interest Margin, Stock Market Capitalization, Value Traded and Turnover. The first principal component accounts for $49 \%$ of the variation in these seven indicators. In Appendix Table A2.4 the coefficients of each financial indicator for $F D$ indicate the negative correlations between the Overhead Cost and Net Interest Margin and $F D$, and the positive correlations between the rest and $F D$.

(2) A second measure, FDBANK, captures the extent of bank-based intermediation. It uses five indicators, Liquid Liabilities, Private Credit, Commercial-central Bank, Overhead Costs and Net Interest Margin. FDBANK accounts for $61 \%$ of the variation in these five indicators.

(3) A third measure, FDSTOCK is a measure of stock market development, based on Stock Market Capitalization, Value Traded and Turnover. FDSTOCK accounts for $66 \%$ of the variations in these financial indices.

(4) A fourth measure, FDEFF, captures financial efficiency. The four indicators of financial efficiency used are Overhead Cost, Net Interest Margin, Value Traded and Turnover. FDEFF accounts for 54\% of the total variation in these indicators. Lower values of this index indicate a higher level of financial efficiency.

(5) A fifth measure, FDSIZE, based solely on Liquid Liabilities and Stock Market Capitalization, captures the size of financial system (also called "financial depth"). The first principal component of these two measures accounts for $81 \%$ of the variation.

\subsubsection{The potential determinants}

Potential determinants of financial development considered in this analysis are widely selected from various sources. To discover the structural determinants of financial development, they are either those "predetermined" like fixed factors, or those "evolving slowly over time" like some institutional factors which are averaged over 1960-89. All variables that could potentially cause serious endogeneity problems are excluded. ${ }^{5}$ The candidate determinants are grouped into four categories as showed in Appendix Table A2.1. The problem of missing data has been addressed by using a set of fixed factors as independent variables to impute the missing data. The fixed factors used include some regional dummies, dummies for income levels and geographic factors for which we have a complete set of data. The imputation procedure is summarized in Appendix Table A2.5. 


\subsubsection{Institutional variables}

This analysis firstly considers legal origin dummies from the GDN dataset in the work by La Porta et al. $(1997,1998)$ on the legal determinants of financial development. The relevant variables are the common law legal origin dummy (COMLEG) for countries with British legal origin and a civil law legal origin dummy (CIVLEG) for countries with French, Germany and Scandinavian legal origins. Two variables closely related to the financial system itself are also considered. ${ }^{6}$ Taken from the dataset of La Porta et al. (1998), SRIGHT is the aggregate index for shareholders' rights ranging from 0 to 6 , while CRIGHT is the aggregate index for creditors' rights ranging from 0 to 4 . These variables measure directly the extent to which the government protects the rights of shareholders and creditors.

In addition, this research makes use of some general institutional indicators. POLITY2 and DURABLE are taken from the PolityIV Database (Marshall and Jaggers, 2009), and averaged over 1960-89. POLITY2 is an index of democracy, seeking to reflect government type and institutional quality based on freedom of suffrage, operational constraints and balances on executives and respect for other basic political rights and civil liberties. It is called the "combined polity score", equal to the democracy score minus the autocracy score. The democracy and autocracy scores are derived from six authority characteristics (regulation, competitiveness and openness of executive recruitment, operational independence of chief executive or executive constraints and regulation and competition of participation). Based on these criteria, each country is assigned a democracy score and autocracy score ranging from 0 to 10 . Accordingly, POLITY 2 ranges from -10 to 10 with higher values representing more democratic regimes. DURABLE is an index of political stability, using the number of years since the last transition in the type of regime or independence. The next variable is FREE, the average of the indices of civil liberties and political rights from the Freedom House Country Survey (2008) over 1972-89. Higher ratings indicate better civil liberties and political rights such as freedom to develop views, institutions and personal autonomy from government. I also employ KKM and PCI. The KKM measure from Kaufmann et al. (2008) is a widely used indicator of the quality of government in a broader sense, derived by averaging six measures of government quality: voice and accountability, political stability and absence of violence, government effectiveness, light regulatory burden, rule of law and freedom from graft. The variable PCI, measuring narrowly the constraints on the executive, is derived by Henisz 
(2000). The last institutional variable I use is EURO1900, the percentage of population that was European or of European descent in 1900, taken from Acemoglu et al. (2001).

Although missing values for EURO1900, SRIGHT, CRIGHT and the market share of state-owned media (discussed below) are imputed, the variable EURO1900 appears only in the developing country sample while the others appear only in the La Porta sample.

\subsubsection{Policy variables}

To examine whether macroeconomic policy variables explain crosscountry variation in financial development, this research makes extensive use of five economic volatility indicators and three trade openness indicators. It uses output volatility and inflation volatility to capture macroeconomic mismanagement and fluctuations. The output volatility measure $(S D G R)$ is defined as the standard deviation of the annual growth rate of real, chain-weighted GDP per capita over 1960-89 from the Penn World Table 6.2. Inflation volatility (SDPI) is defined as the standard deviation of the annual inflation rate over 1960-89 from the World Development Indicators (2008). Taken from the GDN, the volatility of the black market premium (SDBMP), volatility of the terms of trade $(S D T T)$ and trading partners' output volatility $(S D T P)$ are used to reflect the extent of external shocks. SDBMP is defined as the standard deviation of the annual black market premium (BMP) over 1960-89. SDTT is defined as the standard deviation of the first log-differences of a terms of trade index for goods and services. SDTP is the standard deviation of trading partners' GDP per capita growth (weighted average by trade share).

To assess the role of trade factors, this research uses dummies for fuel and non-fuel primary goods exporting countries (EXPPRIM) and manufactured goods exporting countries (EXPMANU) from the GDN. A trade openness policy index, TOPEN, available from the database of Harvard University's Center for International Development (Gallup et al., 1999), is utilized to measure the extent of openness to external trade in the presence of government intervention over 1965-90, while the trade share proposed by Frankel and Romer (1999), denoted by CTRADE, is employed to capture natural openness to external trade. CTRADE is derived by Frankel and Romer (1999) by summing up all bilateral trade with all potential trading partners from a bilateral trade equation that controls for population and land area of the home country and trading partners, the distance between any two trading partners and whether or not the home country is landlocked. 


\subsubsection{Geographic variables}

To examine the role of geography, this study takes six regional dummies from the GDN for East Asian and Pacific countries (REGEAP), Middle Eastern and North African countries (REGMENA), Western European and North American countries (REGWENA), South Asian countries (REGSA), Sub-Saharan African countries (REGSSA) and Latin American and Caribbean countries (REGLAC), respectively. It also uses the following two geographic variables from the GDN. The landlocked variable (LANDLOCK) is a dummy variable that takes the value of 1 if the country has no coastal access to the ocean, and 0 otherwise. There are 17 landlocked countries in the whole sample. Absolute latitude (LATITUDE) equals the absolute distance of a country from the Equator. The closer to the equator the countries are, the more tropical climate they have. ${ }^{7}$ Latitude potentially has an institutional interpretation since smaller absolute latitudes are associated with more unfavourable environments, which are associated with weaker institutions according to the settler mortality hypothesis of Acemoglu et al. (2001). The land area (AREA) in square kilometres for each country, taken from Hall and Jones (1999), is in logs.

This study also makes use of three additional geographic variables. One is POP100CR from the database of Harvard University's Center for International Development. It is the 1994 share of population within $100 \mathrm{~km}$ of a coast or navigable river for a country. Another is MINDIST, based on data from Jon Haveman's International Trade website. This captures the minimum distance from the three capital-goods-supplying centres in the world (USA, Japan and the EU, the centre of the latter represented by Belgium). The study uses the logarithm of the minimum distance from the three capital-goods-supplying centres plus one. These variables might be highly correlated with external trade and manufacturing, since lack of access to coasts or rivers navigable to the ocean and geographic remoteness constitute natural disadvantages to external trade. A further variable for geographic endowment is a dummy for the point source natural resource exporting countries (RESPOINT) from Isham et al. (2005), who find that, in comparison to manufacturing exporters and exporters of "diffuse" natural resources (e.g. wheat, rice and animals) and coffee/cocoa natural resources, the exporting countries of "point source" natural resources (e.g. oil, diamonds and plantation crops) are more likely to have severe social and economic divisions, and less likely to develop socially cohesive mechanisms and effective institutional capacities for managing shocks. 


\subsubsection{Other variables}

Other variables included in this analysis are initial income (GDP90), initial population (POP90), an ethnic fractionalization index (ETHNIC), an ethnic polarization index (ETHPOL), a religious fractionalization index (RELIGION), a language fractionalisation index (LANGUAGE), a European first language index (EURFRAC) and the market share of state-owned media, either television or newspapers (MEDSHARE).

The inclusion of the level of GDP per capita in 1990 (GDP90) is stimulated by work such as Greenwood and Smith (1997) on the feedback from growth in the economy to the development of financial markets. Population size is also closely related to indices of financial development since small countries tend to have higher ratios of liquid liabilities and private credit, having the potential to affect the overall results substantially. GDP90 and POP90, the level of the population in 1990, are from the GDN and used in logs.

The variables ETHNIC, RELIGION and LANGUAGE, taken from Alesina et al. (2003), characterize social divisions and cultural differences, as does the variable ETHPOL, which is taken from Reynal-Querol and Montalvo (2005) to capture the extent to which a large ethnic minority faces an ethnic majority in a society. The EURFRAC measure, taken from Hall and Jones (1999), is the fraction of population speaking one of the major languages of Western Europe (English, French, German, Portuguese or Spanish) as a mother tongue. To some extent, this variable reflects not only the culture of the country, but also the history of colonization. It is therefore closely linked to some other variables like EURO1900, CIVLEG and COMLEG.

The market share of stated-owned media (MEDSHARE) is from Djankov et al. (2003), which shows that greater state ownership of the media is associated with less political and economic freedom, inferior governance, less developed capital markets and poor health outcomes. Djankov et al. (2003) consider two kinds of media state ownership. One is press state ownership, the market share of state-owned newspapers out of the aggregate market share of the five largest daily newspapers (by circulation), and the other is television state ownership, the market share of state-owned television stations out of the aggregate market share of the five largest television stations (by viewer). The index used here is the average of the two media state ownerships.

\subsection{Empirical strategy}

This section discusses the empirical strategies for dealing with model uncertainty faced by research on the determinants of financial development, with the central focus placed on BMA and Gets approaches. 
As summarized in the Introduction, substantial research has been done to explore the origins of financial development, leading to a large number of candidate determinants. Essentially the associated theories, developed under specific settings, are not mutually exclusive, raising concern over the robustness of these candidate determinants in any cross-section regression used to explain financial development.

Usually, the uncertainty about the composition of a regression model is called "model uncertainty". To handle the model uncertainty issue, a number of methodologies have been proposed and widely debated. Among others, the Extreme Bounds Analysis (EBA), BMA and Gets are the most famous methods.

To handle the model uncertainty issue, a number of methodologies have been proposed and widely debated. Among others, the EBA, ${ }^{8} \mathrm{BMA}^{9}$ and Gets ${ }^{10}$ are the most widely used methods. Although the BMA and Gets procedures have respective advantages in handling model uncertainty, neither of them is without limits or exempt from criticism. ${ }^{11}$ This research chooses to apply the BMA and Gets procedures jointly to handle model uncertainty in this context. The combination of Gets and BMA analyses has the advantage of incorporating their merits while circumventing some of their limitations. In what follows, I set out the methods of BMA and Gets in more detail.

\subsubsection{Bayesian Model Averaging}

This section begins with a brief review of the development of BMA approach.

Following the seminal work by Levine and Renelt (1992), Sala-i-Martin $(1997 a, b)^{12}$, Fernandez et al. (2001) ${ }^{13}$ and Sala-i-Martin et al. (2004) are among the significant works using BMA to study the robustness of cross-country growth regressions. Based on work by Raftery (1995), Sala-i-Martin et al. (2004) propose a version of BMA called Bayesian Averaging of Classical Estimates (BACE), in which diffuse priors are assumed for the parameters and only one other prior, relating to the expected model size, is required. This approach has generated evidence in favour of Sala-i-Martin (1997a,b)'s original findings as well.

Essentially, BMA treats parameters and models as random variables and attempts to summarize the uncertainty about the model in terms of a probability distribution over the space of possible models. More specifically, it is used to average the posterior distribution for the parameters under all possible models, where the weights are the posterior model probabilities (PMPS). To evaluate these, the BMA uses the Bayesian Information Criterion $(B I C)$ to approximate the Bayes factors which are needed to compute the posterior model probability, whose derivation is described in the Appendix Text. 
Typically, the number of possible models, $2^{p}$ given $p$ candidate variables, is large. Most applications of BMA to larger datasets do not average over all possible models, but use a search algorithm to identify the subset of models with greatest relevance. The Occam's Window and Markov Chain Monte Carlo techniques can be adopted for this purpose. ${ }^{14}$ The approach developed by Hoeting et al. (1996) has the advantage of selecting variables and identifying outliers simultaneously, but requires a larger sample size relative to the regressor set, and so this method will be applied only in Table 2.1 below. The simpler version of BMA used elsewhere in this study follows Raftery et al. (1997) which focuses only on the subset defined by the Occam's Window technique and treats all the worstfitting models outside the subset as having zero posterior probability. Embodying the principle of parsimony, ${ }^{15}$ the use of the Occam's Window technique considerably reduces the number of possible models, and in the meantime encompasses the inherent model uncertainty present. Once the Occam's Window technique excludes the relatively unlikely models, the posterior model probabilities for the well-fitting models are then calculated.

Once we have posterior model probabilities, we are ready to implement a systematic form of inference for different quantities of interest. For example, when the interest is one of the regression parameters being present, whether positive or negative, what we need to do is to sum up the posterior model probabilities for all models in which the parameter is non-zero, be it positive or negative. In Sections 2.4 and 2.5 below, on the empirical results, the output of the BMA analysis includes the posterior inclusion probabilities for variables and a sign certainty index. The posterior inclusion probability (PIP) for any particular variable is the sum of the posterior model probabilities for all of the models including that variable. The higher the posterior probability for a particular variable, the more robust that determinant for financial development appears to be. For PIPs greater than 0.20, a sign certainty index rather than sign certainty probability is presented, indicating whether the relationship appear to be either positive or negative. ${ }^{16}$

\subsubsection{General-to-specific approach}

The Gets modelling strategy starts from the most general unrestricted model (GUM), which is assumed to characterize the essential datagenerating process (DGP), applies standard testing procedures to eliminate statistically insignificant variables and ends up with a "congruent" final model, which should be free of significant mis-specification. Hoover and Perez (1999) make important advances in practical modelling, like 
the multiple-path approach to Gets model selection. Based on these, the PcGets algorithm has been developed to embody the principles of the underlying theory of Gets reductions extensively discussed in Hendry (1995).

The selection of models by PcGets roughly includes three stages. ${ }^{17}$

The first stage concerns the estimation and testing of the GUM. The GUM should be formulated carefully based on previous empirical and theoretical findings, institutional knowledge and data characteristics. The specification of the GUM should be sufficiently general with a relatively orthogonal parameterization for the $N$ candidate regressors. The next step is to conduct a mis-specification test for "congruence" of the initial GUM. The congruence of the initial GUM is maintained through the selection process to ensure a congruent final model. Once the congruence of the GUM is established, pre-search reduction tests are conducted at a loose significance level. The statistically insignificant variables are eliminated both in blocks and individually, and the GUM reformulated as the baseline for the next stage.

The second stage is the search process. Many possible reduction paths are investigated to avoid path-dependent selection. The terminal model emerges from each path when all reduction diagnostic tests are valid and all remaining variables are significant. At the end of the path searches, all distinct terminal models are collected and tested against their union to find an un-dominated encompassing contender. If a unique model results, it is selected; otherwise, the "surviving" terminal models form a union as a new starting point for reduction. The search process continues until a unique model occurs, or the union coincides with either the original GUM or a previous union. If a union made up of mutually encompassing and un-dominated models results, PcGets employs the $B I C$ to select the unique final model.

The third stage is the post-search evaluation. At this stage PcGets uses post-selection reliability checks to evaluate the significance of variables in the final model selected in two overlapping subsamples.

Obviously, the choice of critical values for pre-selection, selection encompassing tests and subsample post-selection is important for the success of the PcGets algorithm. It provides two basic strategies, liberal and conservative, for the levels of significance, degree of pretesting and so on. The liberal strategy tries to equate the probability of deleting relevant and retaining irrelevant variables, whilst the conservative strategy tries to reduce the chance of retaining irrelevant variables. The choice of different strategies hence affects the chance of either retaining irrelevant variables or dropping relevant variables. Throughout the chapter, PcGets 
is conducted with a more liberal strategy than the default setting of the "liberal strategy" as presented in Appendix Table A2.6, ${ }^{18}$ aiming to keep all promising variables in the final model. The final conclusions are then based on the intersection of the BMA and Gets results.

\subsection{Empirical results (I): Overall financial development}

This section begins studying the determinants of various indices of financial development. The BMA and Gets methods are applied and compared in three different samples (the whole sample, the developing country sample and the La Porta sample) for each index. This section, the central contribution of this analysis, studies the determinants of overall financial development $(F D)$. Section 2.5 is concerned with the determinants for four specific indexes of financial development, followed by a study of the determinants of bond market development.

\subsubsection{Some stylized facts}

As a starting point, it might be useful to look at some stylized facts on the links between some important institutional, policy and geographic variables and $F D$. These figures are based on the whole sample.

Figure 2.1 presents two scatter plots for the links between institutions and financial development. Better institutional quality, captured by KKM, and a more democratic regime, captured by POLITY2, are associated with higher values for $F D$. The trade policy index denoted by TOPEN and Frankel-Romer trade share denoted by CTRADE are positively related to $F D$ in Figure 2.2. The upper chart of Figure 2.3 indicates that countries closer to the main world market centres achieve a higher level of $F D$, while the lower chart shows that financial markets in countries further from the equator are relatively more advanced.

Figure 2.4 portrays the evolution of averaged liquid liability ( $L L Y$ ) over 1960-2003 by different country groups. Note from the upper-left chart that countries in all income groups experienced an increase in $L L Y$, although higher-income countries remain at a higher level of financial development than lower-income countries throughout. The upper-right chart shows considerable differences in averaged $L L Y$ between manufactured goods exporting countries and primary goods exporters in which the latter remain at lower levels or at least partially financially repressed. The lower-left chart shows that the level of $L L Y$ in West European and North American countries was much higher and more stable than that in other country groups. The development process of $L L Y$ in East Asian and Pacific countries was much more pronounced relative to that in any other country group. In the lower-right chart, the development performance 

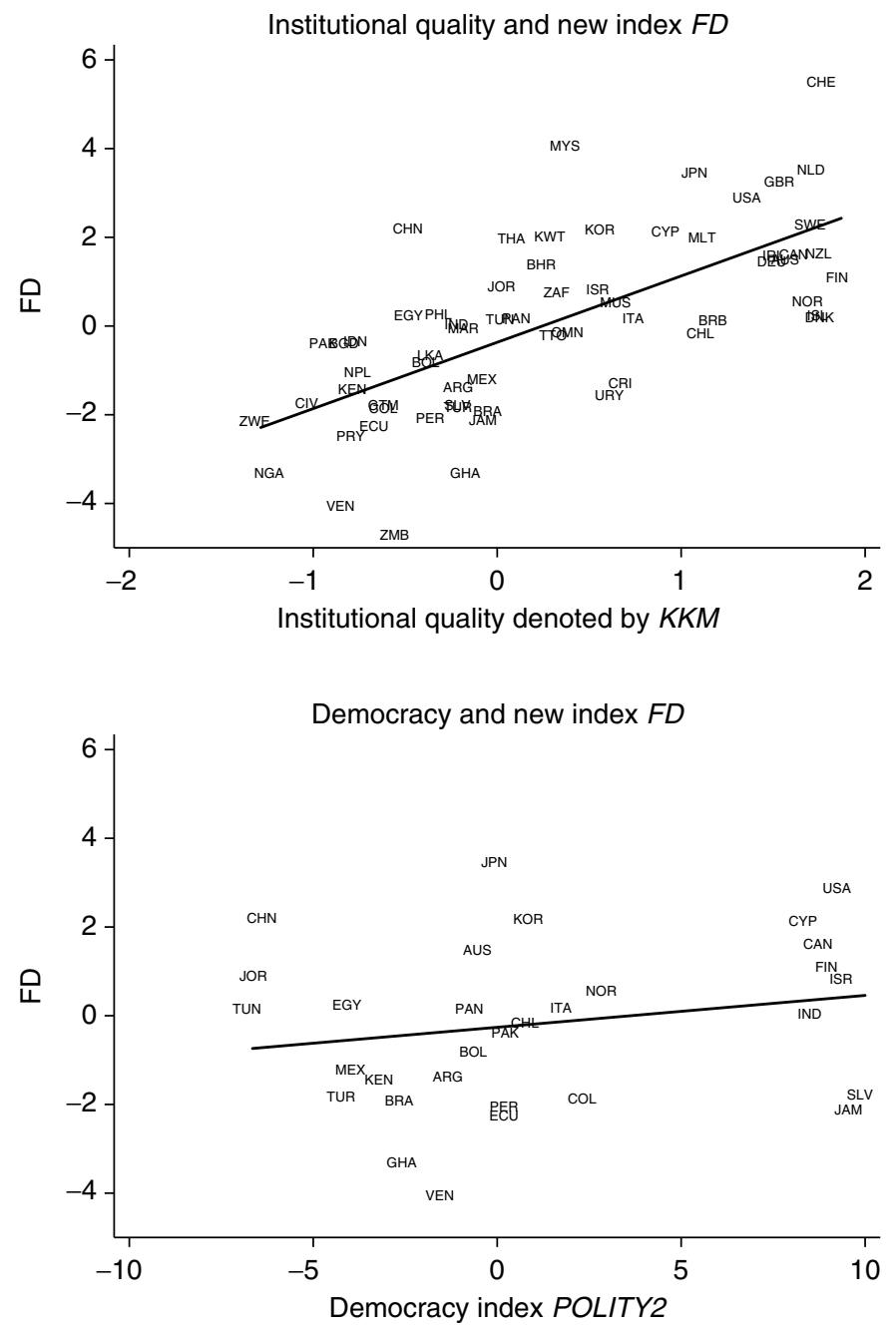

Figure 2.1 Scatter plots of institutions and financial development

Note: Variables and data sources are described in Appendix Table A2.1. These figures show scatter plots of the institutional quality denoted by $K K M$, and the democracy index POLITY2, against the new index FD.

of $L L Y$ in common law countries was in general much more gradual, with the whole process stretching over four decades compared to that in civil law countries, which experienced surges in the 1970s and late 1990s, but a decline in the late 1980s. 

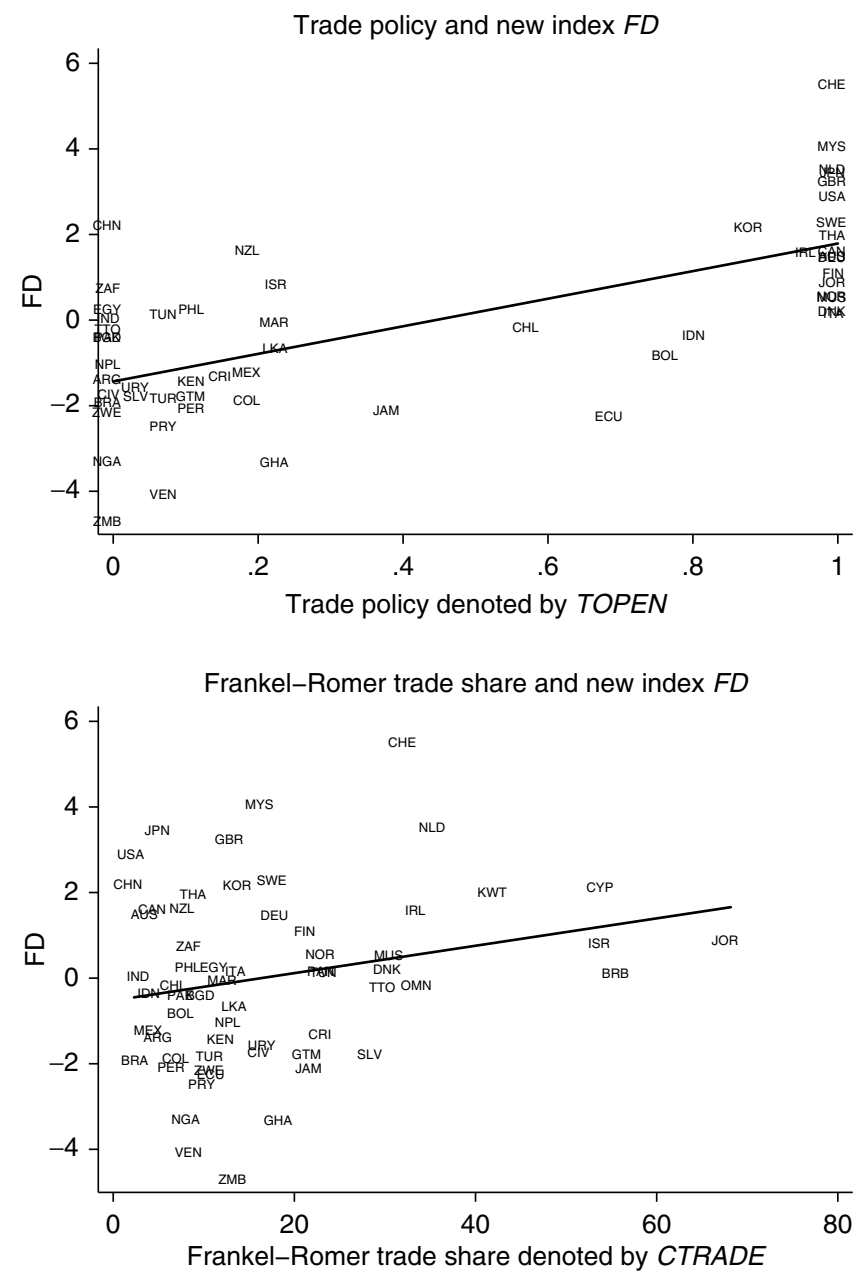

Figure 2.2 Scatter plots of policy and financial development

Note: Variables and data sources are described in Appendix Table A2.1. These figures show scatter plots of the trade policy index from Gallup et al. (1999), and the trade share constructed by Frankel and Romer (1999), against the new index $F D$.

The figures above have shown some interesting facts on the determinants of $F D$. However, a clear conclusion on the robustness of any variable presented cannot readily be drawn. The task of the subsequent Section 2.4 .2 is to examine these links more systematically. 

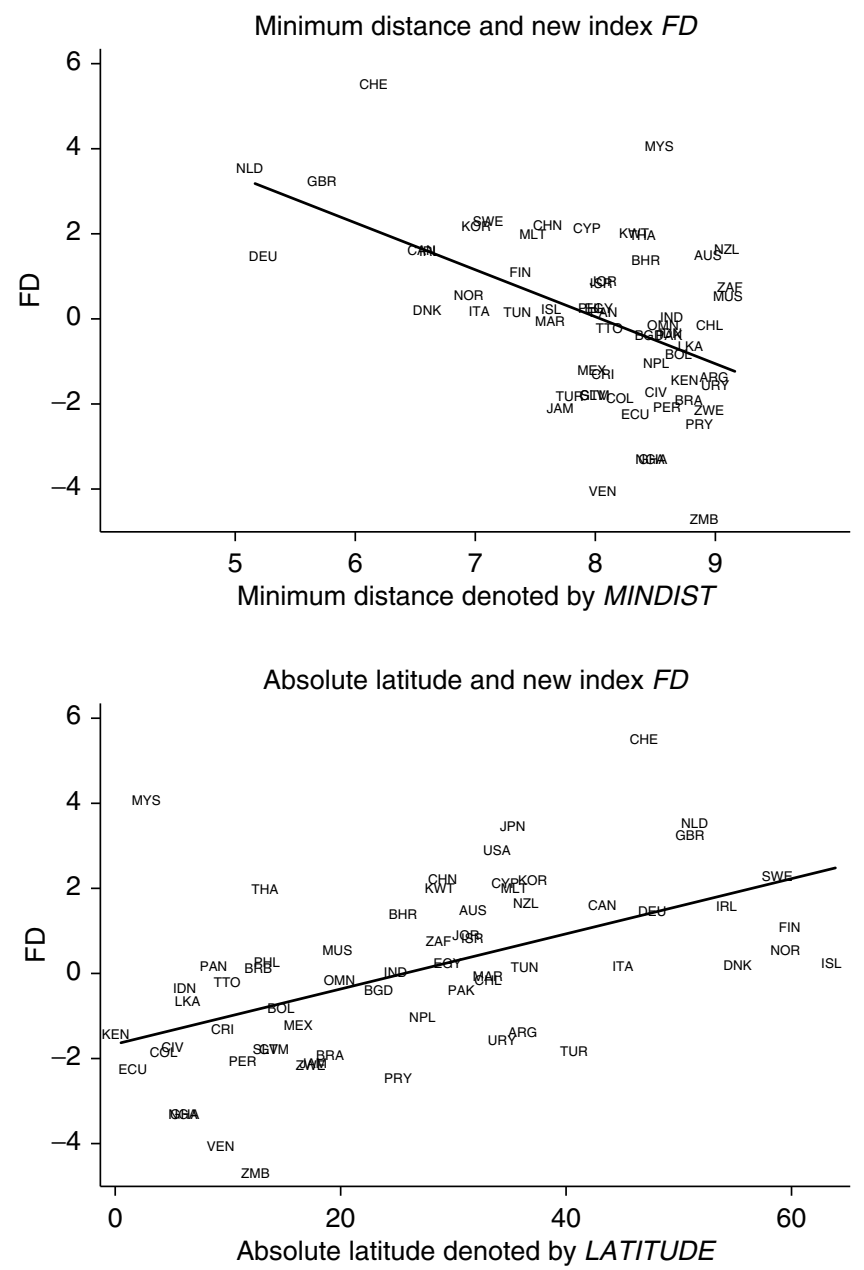

Figure 2.3 Scatter plots of geography and financial development

Note: Variables and data sources are described in Appendix Table A2.1. These figures show scatter plots of the logarithm of minimum distance, and the absolute latitude, against the new index $F D$.

\subsubsection{What are the main determinants of $F D$ ?}

As mentioned earlier, much research regards institutions as the fundamental factor in long-run growth, and some even argue that the only effect of geography on development is via institutions (Acemoglu et al., 

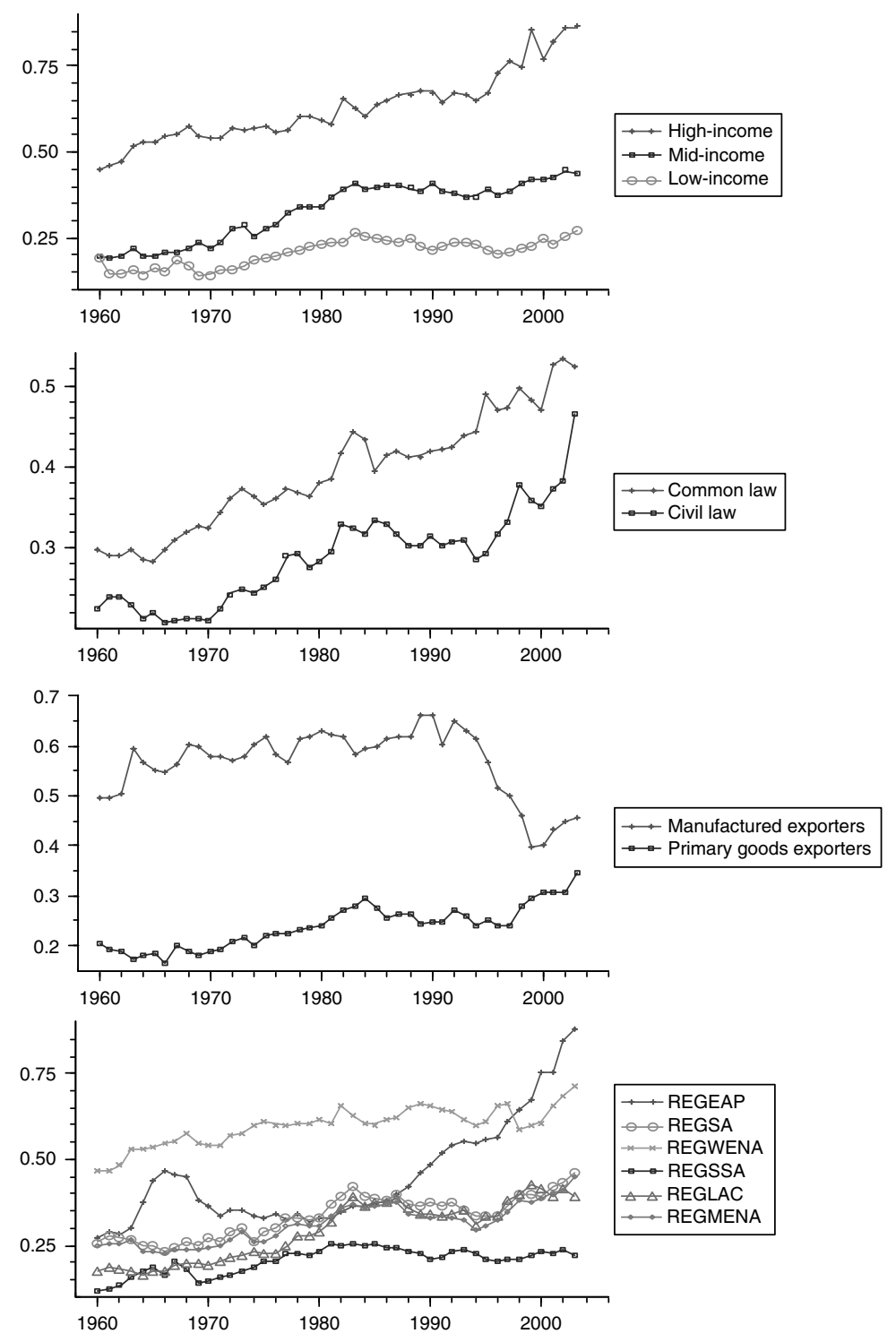

Figure 2.4 Median Liquid Liability by different country group over 1960-2003 Note: Variable descriptions are from Appendix Table A2.1. These figures plot the median liquid liabilities by different income groups in the upper-left chart, countries with different law traditions in the upper-right chart, different exporting countries in the lower-left chart and different regions in the lower-right chart over 1960-2003. 
2001; Dollar and Kraay, 2003; Easterly and Levine, 2003 and Rodrik et al., 2004). Before proceeding to study the main determinants of overall $F D$, this section starts by testing the hypothesis of whether any of three determinants (institutions, policy and geography), considered as a whole, dominates the other two.

Table 2.1 reports the BMA results for determinants of $F D$, which is measured over 1990-99, for 64 countries in the whole sample. All possible explanatory variables are grouped into four blocks in the order of "other" variables, geographic variables, policy variables and institutional variables. In addition to including the "other" variables, models 1-3 include any two of the three blocks (geographic variables, policy variables and institutional variables) to examine the combined effects of any two types of determinants on FD. ${ }^{19}$

The BMA analysis yields posterior inclusion probabilities (either "PIPs" or " $M C^{3 ")},{ }^{20}$ the total posterior model probabilities for the set of models which include a given variable of interest and the sign certainty index ("Sign") of a relationship discussed above. The PIPs are the posterior inclusion probabilities calculated by using the method from Raftery (1995). A sign certainty index is provided where the PIPs are above 0.2 . The $M C^{3}$ denotes the posterior inclusion probabilities computed by using the Markov Chain Monte Carlo techniques due to Hoeting et al. (1996), which conduct variable selection and outlier identification simultaneously. Any $M C^{3}$ greater than 0.2 is shown in bold.

Looking at the first block of "other" variables across models, we note that initial income, GDP90, appears to be important in almost all models with a high posterior probability of inclusion, meaning that, as expected, the level of GDP per capita is fundamental in explaining the crosscountry variation in $F D$. Other variables in this block exhibit varying explanatory power for $F D$. Models 1 and 2 present the effect of geography on $F D$ when policy and institutions, respectively, are controlled for. The effect of geography on $F D$ doesn't seem to disappear when the institutional variables are present, implying that the usual claim that geography works through institutions is not necesarily true in this context. The two BMA methods show that two regional dummies (REGSSA and REGLAC) appear to be closely related to $F D$, meaning that a number of developing countries in these regions are associated with higher levels of financial development in the 1990s, conditional on other variables. The regional dummy REGEAP and land area (AREA) also appear to be important predictors of $F D$ when institutions are controlled for. Similarly, policy has a significant effect on $F D$ in the presence of geography and institutions (Models 1 and 3). Among others, at least EXPPRIM is significant in both 
Table 2.1 Determinants of $F D$ by using BMA

\begin{tabular}{|c|c|c|c|c|c|c|c|c|c|}
\hline \multirow[b]{4}{*}{ Variable } & \multicolumn{3}{|c|}{ Whole } & \multicolumn{3}{|c|}{ Whole } & \multicolumn{3}{|c|}{ Whole } \\
\hline & \multicolumn{3}{|c|}{64} & \multicolumn{3}{|c|}{64} & \multicolumn{3}{|c|}{64} \\
\hline & \multicolumn{3}{|c|}{1} & \multicolumn{3}{|c|}{2} & \multicolumn{3}{|c|}{3} \\
\hline & PIPs & Sign & $M C^{3}$ & PIPs & Sign & $M C^{3}$ & PIPs & Sign & $M C^{3}$ \\
\hline CONSTANT & 1.000 & $(-)$ & & 1.000 & $(-)$ & & 1.000 & $(-)$ & \\
\hline GDP90 & 0.466 & $(+)$ & 0.342 & 0.941 & $(+)$ & 0.488 & 0.744 & $(+)$ & 0.689 \\
\hline РОР90 & 0.000 & & 0.026 & 0.969 & $(+)$ & 0.839 & 0.941 & $(+)$ & 0.517 \\
\hline ETHPOL & 0.004 & & 0.039 & 0.649 & $(+)$ & 0.070 & 0.906 & $(+)$ & 0.035 \\
\hline ETHNIC & 0.000 & & 0.028 & 0.014 & 0.962 & 0.000 & & 0.333 & \\
\hline RELIGION & 1.000 & $(+)$ & 0.029 & 0.056 & & 0.071 & 0.099 & & 0.029 \\
\hline$L A N G U A G E$ & 0.000 & & 0.056 & 0.036 & 0.995 & 0.000 & & 0.962 & \\
\hline EURFRAC & 0.000 & & 0.992 & 0.706 & $(-)$ & 0.040 & 0.982 & $(-)$ & 0.089 \\
\hline REGEAP & 0.186 & & 0.132 & 0.726 & $(+)$ & 0.958 & & & \\
\hline REGMENA & 0.314 & $(+)$ & 0.176 & 0.006 & & 0.060 & & & \\
\hline REGSA & 0.186 & & 0.110 & 0.053 & & 0.037 & & & \\
\hline REGSSA & 0.879 & $(-)$ & 0.946 & 0.642 & $(-)$ & 0.049 & & & \\
\hline REGLAC & 0.872 & $(-)$ & 0.942 & 0.385 & $(-)$ & 0.071 & & & \\
\hline REGWENA & 0.204 & $(-)$ & 0.175 & 0.036 & & 0.094 & & & \\
\hline$L A N D L O C K$ & 0.000 & & 0.065 & 0.003 & 0.208 & & & & \\
\hline LATITUDE & 0.000 & & 0.056 & 0.386 & $(-)$ & 0.063 & & & \\
\hline AREA & 0.073 & & 0.034 & 0.975 & $(-)$ & 0.831 & & & \\
\hline MINDIST & 0.030 & & 0.032 & 0.012 & & 0.623 & & & \\
\hline POP100CR & 0.051 & & 0.027 & 0.400 & $(-)$ & 0.056 & & & \\
\hline RESPOINT & & 0.037 & 0.005 & 0.025 & & & & & \\
\hline TOPEN & 0.850 & $(+)$ & 0.927 & & & & 0.045 & & 0.309 \\
\hline CTRADE & 0.099 & & 0.049 & & & & 0.215 & $(+)$ & 0.050 \\
\hline EXPMANU & 0.000 & & 0.030 & & & & 0.000 & & 0.025 \\
\hline EXPPRIM & 0.409 & $(-)$ & 0.175 & & & & 0.999 & $(-)$ & 0.964 \\
\hline$S D G R$ & 0.000 & & 0.031 & & & & 0.000 & & 0.069 \\
\hline$S D B M P$ & 0.252 & $(-)$ & 0.192 & & & & 0.000 & & 0.126 \\
\hline$S D P I$ & 0.076 & & 0.030 & & & & 0.064 & & 0.053 \\
\hline SDTP & 0.000 & & 0.023 & & & & 0.398 & $(+)$ & 0.228 \\
\hline$S D T T$ & 0.329 & $(-)$ & 0.201 & & & & 0.045 & & 0.026 \\
\hline CIVLEG & & & & 0.589 & $(-)$ & 0.740 & 0.461 & $(-)$ & 0.867 \\
\hline COMLEG & & & & 0.361 & $(-)$ & 0.358 & 0.128 & & 0.467 \\
\hline POLITY2 & & & & 0.291 & $(+)$ & 0.051 & 0.258 & $(+)$ & 0.050 \\
\hline DURABLE & & & & 0.300 & $(+)$ & 0.058 & 0.022 & & 0.031 \\
\hline FREE & & & & 0.020 & & 0.069 & 0.006 & & 0.084 \\
\hline$K K M$ & & & & 0.988 & $(+)$ & 1.000 & 1.000 & $(+)$ & 0.999 \\
\hline$P C I$ & & & & 0.963 & $(-)$ & 0.996 & 0.924 & $(-)$ & 0.953 \\
\hline EURO1900 & & & & & & & & & \\
\hline MEDSHARE & & & & & & & & & \\
\hline SRIGHT & & & & & & & & & \\
\hline CRIGHT & & & & & & & & & \\
\hline
\end{tabular}

Note: The dependent variable $F D$ is the aggregate index of overall financial development over period, 199099. Variable description is in Appendix Table A2.1. BMA yields the posterior probabilities of inclusion (either "PIPs" or "MC 3 "), the total posterior model probabilities for all models including a given variable and the sign certainty index of a relationship ("Sign"). A sign is given to PIPs greater than 0.2. No sign givern means the sign of estimated relationship being uncertain. Any $\mathrm{MC}^{3}$ greater than 0.2 is in bold. The PIPs is taken from Raftery (1995) while the $\mathrm{MC}^{3}$ is due to Hoeting et al. (1996) who also identify the outliers. 
cases. Neither does the usual claim that policy works through institutions by affecting their quality apply to this context. Models 2 and 3 show that the role of institutions is not altered when geography and policy are controlled for. Note that most of the institutional variables appear to be significant predictors of $F D$, in particular, the $K K M$ (governance index) and PCI (political constraints index) have a posterior probability of inclusion close to 1 .

Overall, Table 2.1 has demonstrated that geography, institutions and policy as a group are all important in the process of financial development, although their effects may be picked up by varied predictors when conditioning on other factors is in place. These results clearly suggest that it would be more appropriate to include all of them in the analysis.

Table 2.2 contains a thorough study of determinants of FD by using BMA and Gets in which the above conclusion (in terms of geography, institutions and policy all being important) is embodied. The BMA analysis reports PIPs and the sign certainty index ("Sign") discussed above. The Gets analysis produces the coefficients and t-values for possible determinants in the final model. It also reports the residual sum-ofsquares (RSS), the equation standard error or residual standard deviation (sigma), the squared multiple correlation coefficient $\left(R^{2}\right)$ and its values adjusted for degree of freedom $\left(R_{\text {adj }}^{2}\right)$, the log-likelihood value and three information criteria: the Akaike Information Criterion (AIC), the Hannan-Quinn Criterion (HQ) and the Schwarz Criterion (SC). The output also includes three mis-specification tests (Chow test, Normality test and Heteroscedasticity test). ${ }^{21}$ The Gets results in Table 2.2 are the final models for three samples, respectively, in Appendix Table A2.7, which clearly shows the variables included in the GUM and in the final model.

In Table 2.2, the BMA analysis for the whole sample yields a subset inclusive of four "other" variables (GDP90, POP90, ETHPOL and EURFRAC), two geographic variables (REGEAP and $A R E A$ ), four policy variables (CTRADE, EXPPRIM, SDBMP and SDPI) and five institutional variables (CIVLEG, COMLEG, DURABLE, KKM and PCI). Given no rejection of the mis-specification tests, the Gets analysis for the whole sample yields a subset inclusive of three "other" variables (GDP90, POP90 and EURFRAC), two geographic variables (LATITUDE and AREA), one policy variable (SDTT) and three institutional variables (CIVLEG, KKM and $P C I$ ). Both the BMA and Gets analyses on the whole sample unanimously suggest that three "other" variables (GDP90, POP90 and EURFRAC), one geographic variable $(A R E A)$ and three institutional variables (CIVLEG, $K K M$ and $P C I$ ) are the main determinants for $F D$. 


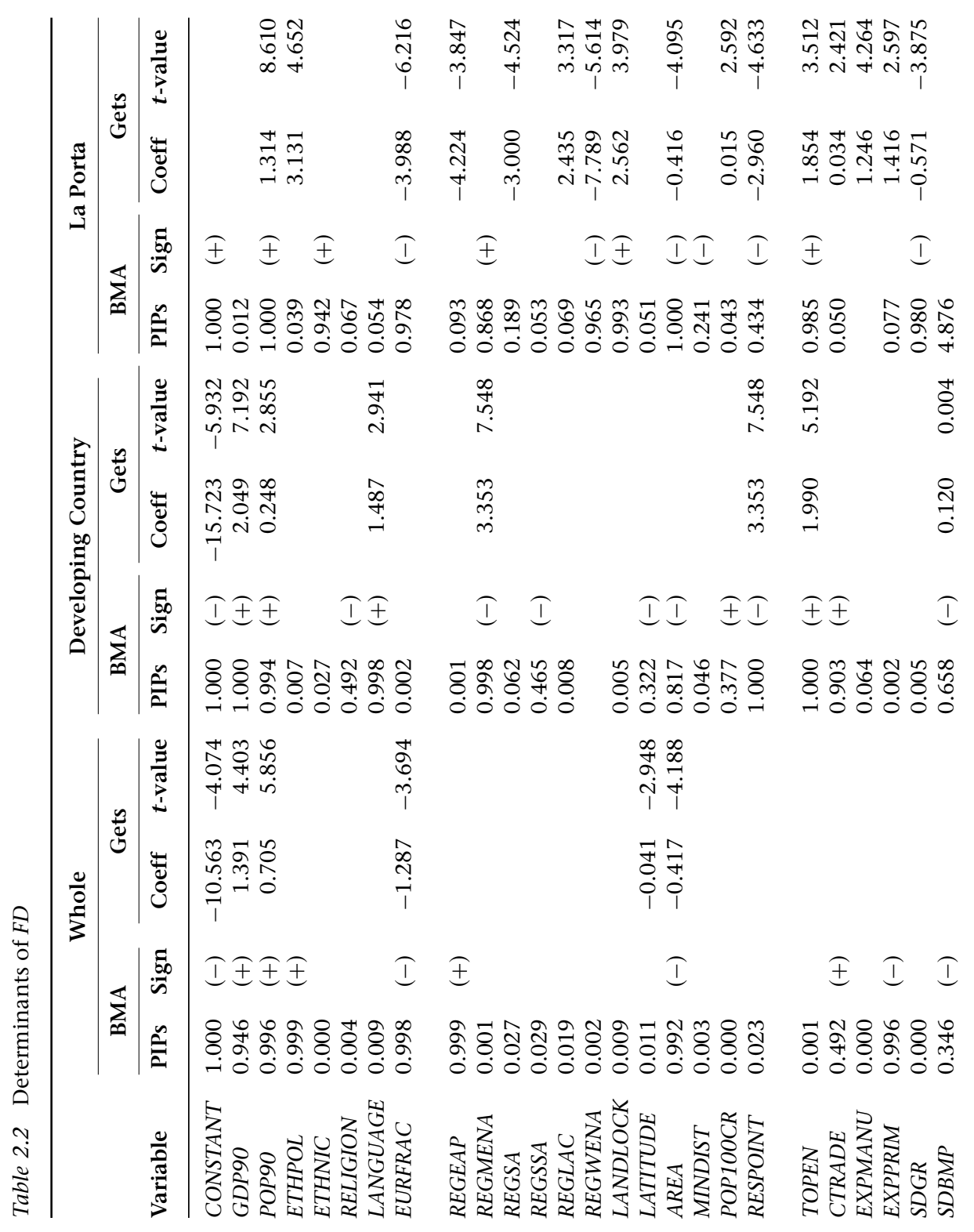




\begin{tabular}{|c|c|c|c|c|c|}
\hline $\begin{array}{l}0 \stackrel{0}{0} \mathbb{N} \\
0 \\
i \\
i \\
i \\
1\end{array}$ & 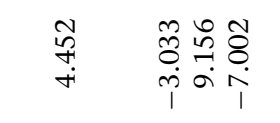 & $\underset{0}{\stackrel{0}{0}}$ & 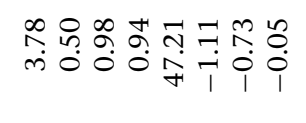 & $\ddot{n}$ & 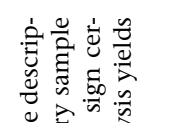 \\
\hline 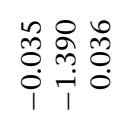 & 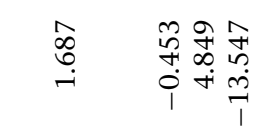 & 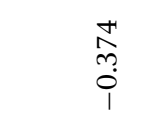 & & $\stackrel{n}{\rightarrow}$ & 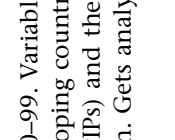 \\
\hline & 𤣩王I & Iモ & & & \\
\hline 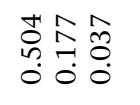 & 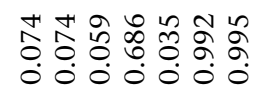 & 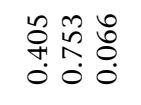 & & & 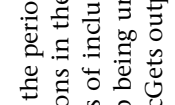 \\
\hline & 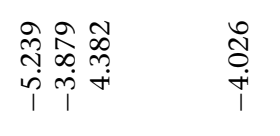 & & 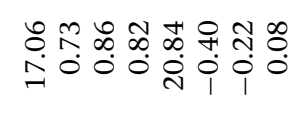 & 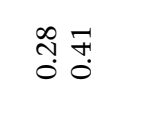 & \\
\hline & 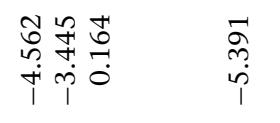 & & & 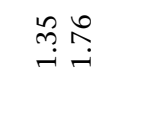 & \\
\hline & III 王I & & & & \\
\hline $\begin{array}{l}n \\
\vdots \\
\vdots \\
0 \\
0 \\
0 \\
0\end{array}$ & 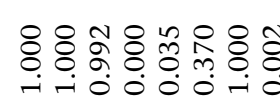 & & & & \\
\hline$\underset{\substack{i \\
i}}{i}$ & 苔落 & & 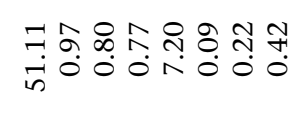 & $\stackrel{\infty}{0}: 5$ & \\
\hline 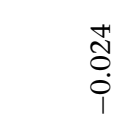 & 赵赵 & & & 苾 & \\
\hline & I王王王I & & & & \\
\hline$m$ & 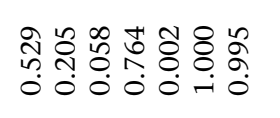 & & & & \\
\hline
\end{tabular}


Table 2.3 Top ten models and their posterior probabilities for $F D$

\begin{tabular}{lcccccccccc}
\hline & 1 & 2 & 3 & 4 & 5 & 6 & 7 & 8 & 9 & 10 \\
\hline GDP9O & $*$ & $*$ & $*$ & $*$ & $*$ & $*$ & $*$ & $*$ & $*$ & $*$ \\
POP9O & $*$ & $*$ & $*$ & $*$ & $*$ & $*$ & $*$ & $*$ & $*$ & $*$ \\
ETHPOL & $*$ & $*$ & $*$ & $*$ & $*$ & $*$ & $*$ & $*$ & $*$ & $*$ \\
EURFRAC & $*$ & $*$ & $*$ & $*$ & $*$ & $*$ & $*$ & $*$ & $*$ & $*$ \\
REGEAP & $*$ & $*$ & $*$ & $*$ & $*$ & $*$ & $*$ & $*$ & $*$ & $*$ \\
AREA & $*$ & $*$ & $*$ & $*$ & $*$ & $*$ & $*$ & $*$ & $*$ & $*$ \\
ETRADE & & & $*$ & $*$ & $*$ & & $*$ & $*$ & & \\
SDBPRIM & $*$ & $*$ & $*$ & $*$ & $*$ & $*$ & $*$ & $*$ & $*$ & $*$ \\
SDPI & $*$ & $*$ & $*$ & $*$ & $*$ & & $*$ & $*$ & $*$ & $*$ \\
SDTT & & & & & & & & & & \\
CIVLEG & $*$ & $*$ & $*$ & $*$ & & $*$ & & & $*$ & \\
DURLEG & & & & & $*$ & & & $*$ & & $*$ \\
KKM & $*$ & & $*$ & $*$ & $*$ & & $*$ & $*$ & $*$ & $*$ \\
PCI & $*$ & $*$ & $*$ & $*$ & $*$ & $*$ & $*$ & $*$ & $*$ & $*$ \\
PMP & 0.048 & 0.042 & 0.042 & 0.037 & 0.030 & 0.028 & 0.028 & 0.028 & 0.028 & 0.025 \\
\hline
\end{tabular}

Note: This table presents the top ten models for $F D$, ranked by their posterior model probability (PMP) in the whole sample. The variable description is in Appendix Table A2.1.

In Tables 2.1 and 2.2, the BMA procedure has yielded PIPs for all candidate variables. A natural question to ask is about the structure of the models, especially the models with higher explanatory power. Table 2.3 lists the structure of the top ten models for $F D$ in the whole sample in terms of posterior model probabilities, serving as a concrete illustration of model selection. A noteworthy point is that all these models have more than ten possible predictors with geographic variables (such as REGEAP, AREA), policy variables (such as EXPPRIM) and institutional variables (like KKM and $P C I$ ) and "other" variables (like GDP90, POP90, ETHPOL and EURFRAC) present in all models. However, one should be aware of the dramatic model uncertainty, reflected by less than $5 \%$ posterior model probabilities for all top ten "best" models, which indicates the potential importance of the BMA and Gets procedures for model selection as a systematic response to pervasive model uncertainty.

Moving on one step further, OLS regressions are used to estimate some of the best performing models in Table 2.4. The best model, that is the model with highest posterior probability in Table 2.3 , is presented in column 4. The "other" variables, like GDP90, POP90 and EURFRAC, are 
Table 2.4 Geography, policy, institutions and FD

\begin{tabular}{|c|c|c|c|c|}
\hline & (1) & (2) & (3) & (4) \\
\hline CONSTANT & $\begin{array}{r}-15.159 \\
{[5.87]^{* *}}\end{array}$ & $\begin{array}{c}-8.220 \\
{[2.95]^{* *}}\end{array}$ & $\begin{array}{c}-10.874 \\
{[3.33]^{* *}}\end{array}$ & $\begin{array}{c}-8.056 \\
{[3.16]^{* *}}\end{array}$ \\
\hline GDP90 & $\begin{array}{c}1.312 \\
{[6.25]^{* *}}\end{array}$ & $\begin{array}{c}0.990 \\
{[2.65]^{*}}\end{array}$ & $\begin{array}{c}1.000 \\
{[2.93]^{* *}}\end{array}$ & $\begin{array}{c}0.958 \\
{[3.01]^{* *}}\end{array}$ \\
\hline РОР90 & $\begin{array}{c}0.521 \\
{[3.66]^{* *}}\end{array}$ & $\begin{array}{c}0.584 \\
{[4.75]^{* *}}\end{array}$ & $\begin{array}{c}0.371 \\
{[3.12]^{* *}}\end{array}$ & $\begin{array}{c}0.512 \\
{[4.72]^{* *}}\end{array}$ \\
\hline ETHPOL & $\begin{array}{r}1.117 \\
{[1.88]}\end{array}$ & $\begin{array}{c}1.584 \\
{[2.89]^{* *}}\end{array}$ & $\begin{array}{r}1.029 \\
{[1.65]}\end{array}$ & $\begin{array}{c}1.496 \\
{[3.17]^{* *}}\end{array}$ \\
\hline EURFRAC & $\begin{array}{c}-0.801 \\
{[2.32]^{*}}\end{array}$ & $\begin{array}{c}-1.138 \\
{[3.84]^{* *}}\end{array}$ & $\begin{array}{c}-1.143 \\
{[3.68]^{* *}}\end{array}$ & $\begin{array}{c}-1.100 \\
{[4.16]^{* *}}\end{array}$ \\
\hline REGEAP & $\begin{array}{c}1.961 \\
{[4.61]^{* *}}\end{array}$ & $\begin{array}{l}1.277 \\
{[3.29]^{* *}}\end{array}$ & & $\begin{array}{c}1.239 \\
{[3.92]^{* *}}\end{array}$ \\
\hline$A R E A$ & $\begin{array}{r}-0.177 \\
{[1.58]}\end{array}$ & $\begin{array}{c}-0.457 \\
{[4.72]^{* *}}\end{array}$ & & $\begin{array}{c}-0.412 \\
{[4.41]^{* *}}\end{array}$ \\
\hline CTRADE & $\begin{array}{c}0.044 \\
{[4.07]^{* *}}\end{array}$ & & $\begin{array}{r}0.025 \\
{[2.01]}\end{array}$ & \\
\hline EXPPRIM & $\begin{array}{c}-0.609 \\
{[1.54]}\end{array}$ & & $\begin{array}{c}-0.970 \\
{[3.11]^{* *}}\end{array}$ & $\begin{array}{c}-0.943 \\
{[4.06]^{* *}}\end{array}$ \\
\hline$S D B M P$ & $\begin{array}{c}-0.001 \\
{[3.79]^{* *}}\end{array}$ & & $\begin{array}{c}0.000 \\
{[0.22]}\end{array}$ & \\
\hline SDPI & $\begin{array}{c}0.001 \\
{[4.12]^{* *}}\end{array}$ & & $\begin{array}{c}0.001 \\
{[3.51]^{* *}}\end{array}$ & $\begin{array}{c}0.001 \\
{[4.50]^{* *}}\end{array}$ \\
\hline SDTT & $\begin{array}{c}-0.010 \\
{[1.20]}\end{array}$ & & $\begin{array}{c}-0.010 \\
{[0.93]}\end{array}$ & \\
\hline CIVLEG & & $\begin{array}{c}-1.159 \\
{[2.22]^{*}}\end{array}$ & $\begin{array}{c}-1.712 \\
{[3.33]^{* *}}\end{array}$ & $\begin{array}{c}-0.600 \\
{[2.49]^{*}}\end{array}$ \\
\hline COMLEG & & $\begin{array}{c}-0.656 \\
{[1.28]}\end{array}$ & $\begin{array}{c}-0.998 \\
{[1.96]}\end{array}$ & \\
\hline DURABLE & & $\begin{array}{c}0.018 \\
{[1.66]}\end{array}$ & $\begin{array}{r}0.011 \\
{[0.73]}\end{array}$ & $\begin{array}{r}0.017 \\
{[1.54]}\end{array}$ \\
\hline$K K M$ & & $\begin{array}{c}1.489 \\
{[4.40]^{* *}}\end{array}$ & $\begin{array}{l}1.237 \\
{[3.30]^{* *}}\end{array}$ & $\begin{array}{c}1.445 \\
{[5.12]^{* *}}\end{array}$ \\
\hline PCI & & $\begin{array}{c}-4.006 \\
{[4.29]^{* *}}\end{array}$ & $\begin{array}{c}-3.791 \\
{[3.98]^{* *}}\end{array}$ & $\begin{array}{c}-4.258 \\
{[4.90]^{* *}}\end{array}$ \\
\hline $\begin{array}{l}\text { Standardized } \\
\text { ETHPOL }\end{array}$ & 0.49 & 0.72 & 0.45 & 0.68 \\
\hline $\begin{array}{l}\text { EURFRAC } \\
\text { AREA }\end{array}$ & $\begin{array}{l}-0.46 \\
-0.15\end{array}$ & $\begin{array}{l}-0.62 \\
-0.29\end{array}$ & -0.63 & $\begin{array}{l}-0.61 \\
-0.26\end{array}$ \\
\hline $\begin{array}{l}\text { CTRADE } \\
\text { SDBMP }\end{array}$ & $\begin{array}{l}-0.04 \\
-0.06\end{array}$ & & $\begin{array}{l}-0.05 \\
-0.06\end{array}$ & \\
\hline $\begin{array}{l}\text { SDPI } \\
\text { SDTT }\end{array}$ & $\begin{array}{l}-0.06 \\
-0.07\end{array}$ & & $\begin{array}{l}-0.06 \\
-0.07\end{array}$ & -0.06 \\
\hline DURABLE & & -0.05 & -0.06 & -0.05 \\
\hline$K K M$ & & 0.68 & 0.55 & 0.66 \\
\hline$P C I$ & & -2.05 & -1.94 & -2.17 \\
\hline Observations & 64 & 64 & 64 & 64 \\
\hline R-square & 0.740 & 0.820 & 0.790 & 0.860 \\
\hline
\end{tabular}

Note: The models are estimated by OLS. The dependent variable is FD, over 1990-99. The t-values are reported in brackets. Variable descriptions are from Appendix Table A2.1. The standardized coefficients show the change of a standard deviation of $F D$ due to a one standard deviation change in a variable for those other than initial GDP and population, binary variables.

$*$,** and $* * *$ significant at $10 \%, 5 \%$ and $1 \%$, respectively. 
found significant in every model. The regional dummy REGEAP is significant in all relevant models, showing that the East Asian and Pacific countries are positively associated with higher FD. While AREA is significant in Models 2 and 4, the standardized coefficient for it is rather small. For the policy variables, EXPPRIM is significant in Models 3 and 4, but not for Model 1. SDPI is significant in all relevant models, but the standardized coefficient for it is negligible. Three institutional variables, CIVLEG, KKM and PCI, are found to be significantly associated with $F D$ in all relevant models. The effects of $K K M$ and $P C I$ on $F D$ are very strong, as shown by the standardized coefficients in the lower section of the table: a one standard deviation change in $K K M$ translates into a more than 0.5 standard deviation of the $F D$ measure, and even stronger effects for PCI.

In sum, on the one hand, the analyses above further confirm that institutions, policy and geography, taken as a group, jointly explain a substantial proportion of the variation in FD. On the other hand, the above analyses show that, in comparison to policy and geography, institutions could play a fundamental role in the process of financial development. When taken individually, at least CIVLEG, KKM, PCI, GDP90, POP90 and EURFRAC are found to have a significant influence on financial development. This finding explicitly suggests that, in addition to initial GDP and initial population, the legal origin ${ }^{22}$ and institutional quality are the most fundamental determinants of financial development in a country.

\subsection{Empirical results (II): Specific financial developments}

This section turns to study briefly the determinants of four specific indices for financial development derived by using principal component analysis, namely, financial intermediary development (FDBANK), stock market development (FDSTOCK), financial efficiency development $(F D E F F)$ and financial size development (FDSIZE). Bond market development (FDBOND) is also studied afterwards. The three samples are investigated for each index in which EURO1900 is available only for the developing country sample while SRIGHT, CRIGHT and MEDSHARE are available only for the La Porta dataset sample.

As in the previous section, the Gets model search is conducted with the relatively liberal strategy presented in Appendix Table A2.6.

The determinants of financial intermediary development (FDBANK) are reported in Table 2.5. The whole sample has 91 observations, the developing country sample has 70 and the La Porta sample has $40 .^{23}$ 
The BMA and Gets analyses on the whole sample suggest FDBANK is positively related to initial income. East Asian and Pacific countries, Middle Eastern and North African countries and South Asian countries witness relative success in financial intermediary development. MINDIST is suggested to be important as well. The trade open policy index (TOPEN) and Frankel-Romer index (CTRADE) are significantly positively signed, suggesting financial intermediary development is boosted by more open trade policies. Three institutional variables (POLITY2, KKM and PCI) are suggested to be determinants for FDBANK, consistent with a conventional view that better institutions are associated with better financial intermediary development. The analyses based on the developing country and La Porta samples in general confirm the findings for GDP90, REGEAP, REGMENA, TOPEN, KKM and PCI. In addition, the analyses from the La Porta sample show that shareholders' right and creditors' rights may be closely related to financial intermediary development.

The determinants of stock market development (FDSTOCK) are reported in Table 2.6. The whole sample has 81 observations, the developing country sample has 50 and the La Porta sample has 49. The BMA and Gets analyses on the whole sample indicate that FDSTOCK is positively related to the initial population and the ethnic polarization index, while it is negatively related to the language fractionalization index (EURFRAC). ${ }^{24}$ East Asian and Pacific countries experience a rise in stock market development. Land area is also important for FDSTOCK. Among other policy factors, TOPEN and SDGR are almost suggested by two methods to be in the model - this finding is also supported in the developing country and La Porta samples. The usual claim concerning the positive impacts of open trade policy on financial development applies here. The significantly negative effect of output volatility on FDSTOCK means that macroeconomic mismanagement might exert an adverse effect on FDSTOCK. Three institutional variables (DURABLE, KKM and PCI) are suggested to be the main determinants for FDSTOCK. The analyses based on the developing country and the La Porta samples support the idea that more open trade policies and better institutions promote stock market development.

The determinants of financial efficiency (FDEFF) are reported in Table 2.7. The whole sample has 79 observations, the developing country sample has 48 and the La Porta sample has 49 . Note that the lower value of $F D E F F$ is associated with a higher level of financial efficiency development as discussed in Section 2.2.2. The BMA and Gets analyses on the whole sample suggest that RELIGION is significantly related to FDEFF. East Asian and Pacific countries, South Asian countries, Middle Eastern 


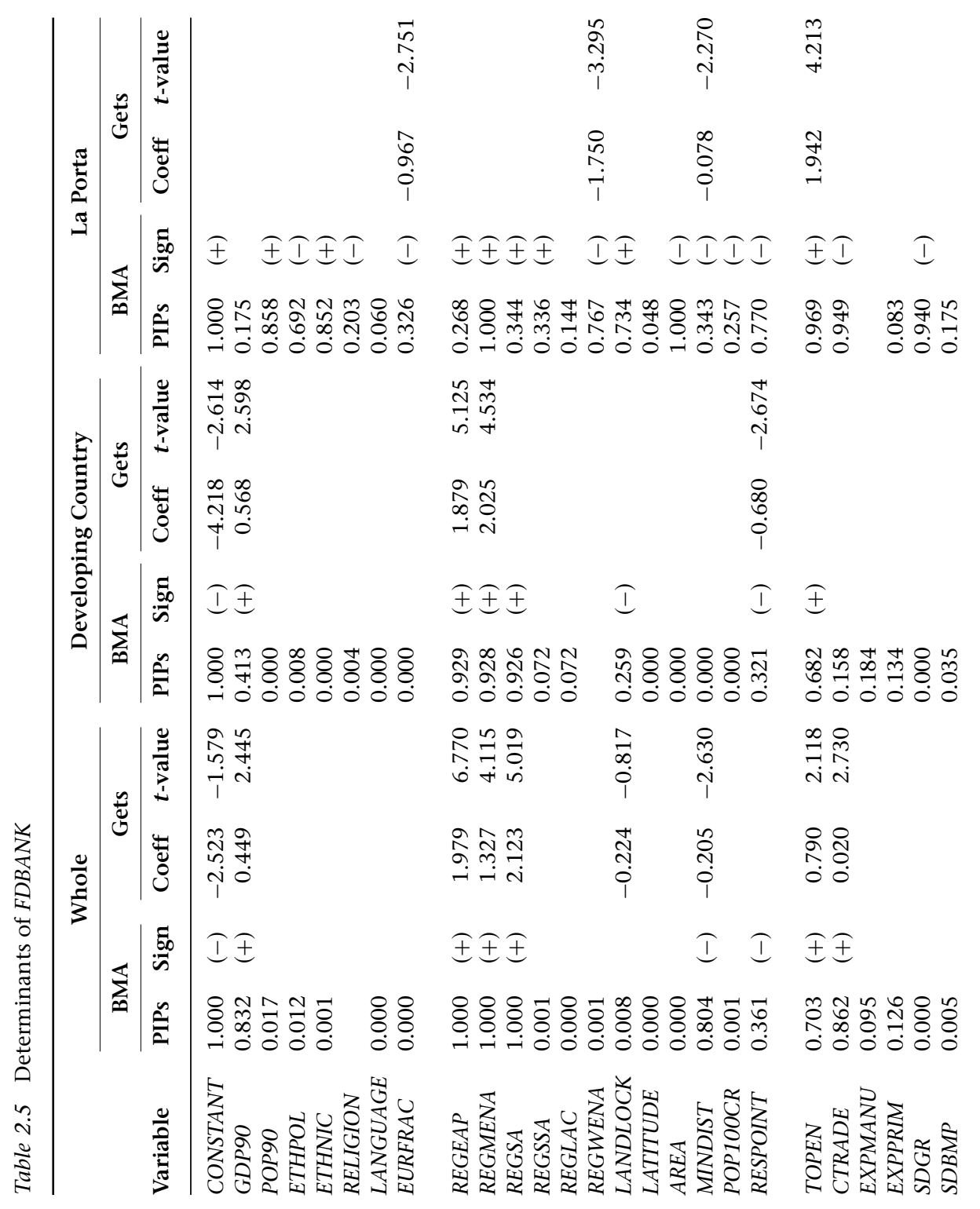




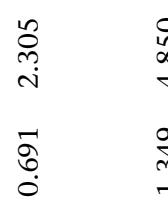

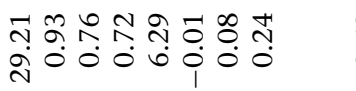

$\ddot{3}$

ọ

II II

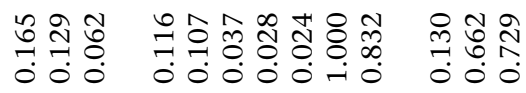

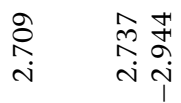

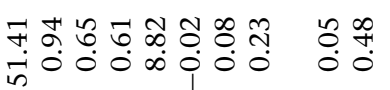

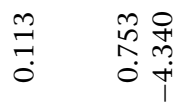

$$
\begin{aligned}
& \text { तิ } \\
& \text { II }
\end{aligned}
$$

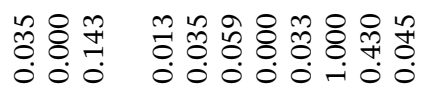

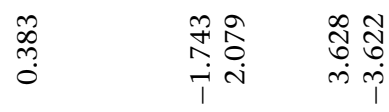

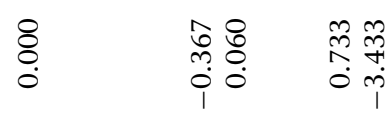

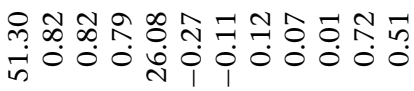

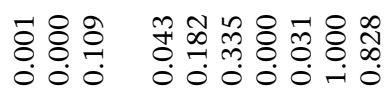

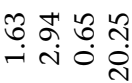

$$
\text { 王王 }
$$




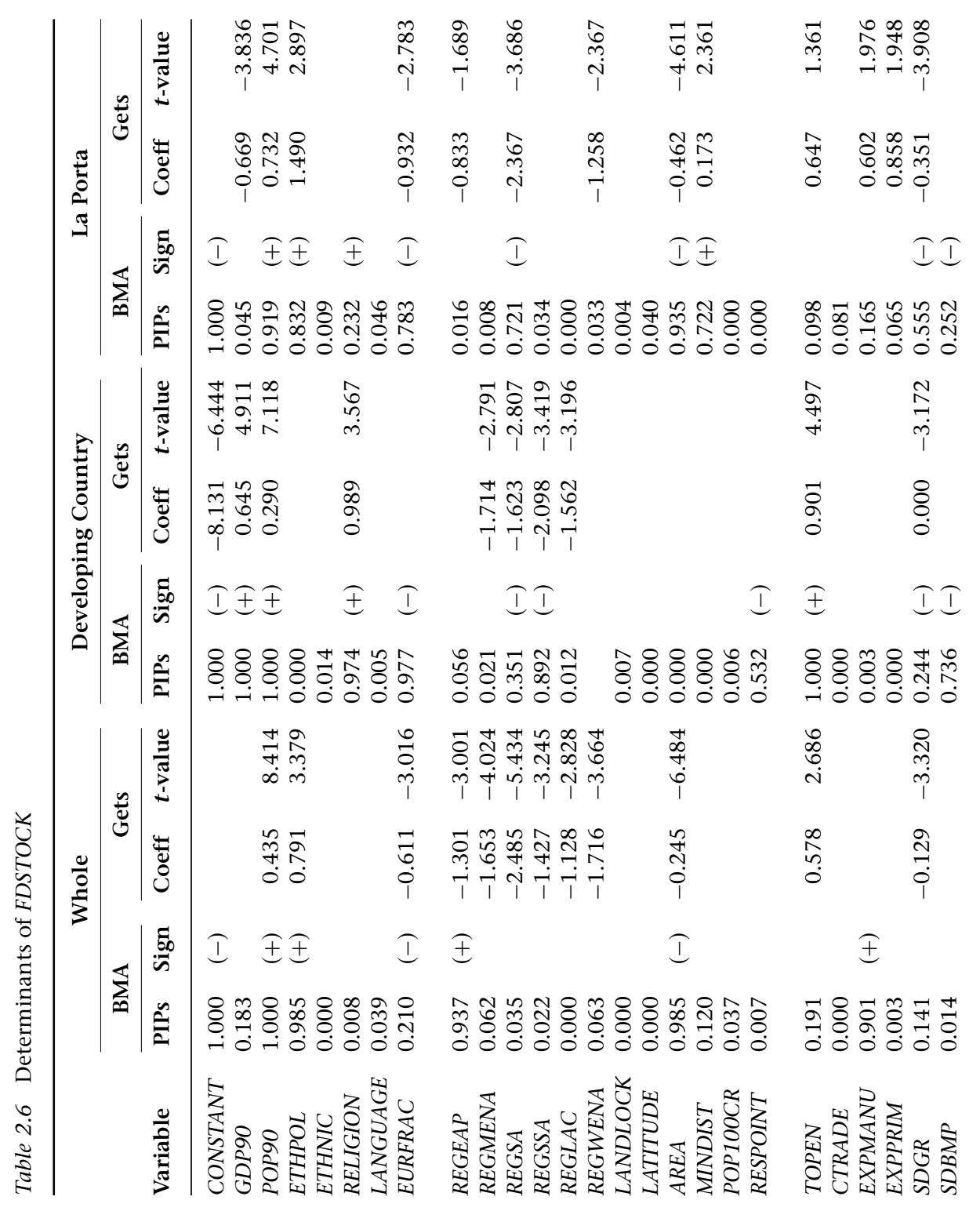




$$
\begin{aligned}
& \begin{array}{lll}
\ddot{n} & \vec{b} & 0 \\
& \stackrel{\vec{r}}{+}
\end{array}
\end{aligned}
$$

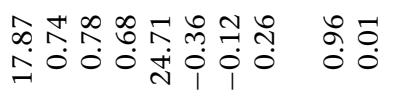

$$
\begin{aligned}
& \text { 垔 } \\
& \text { 王王 I }
\end{aligned}
$$

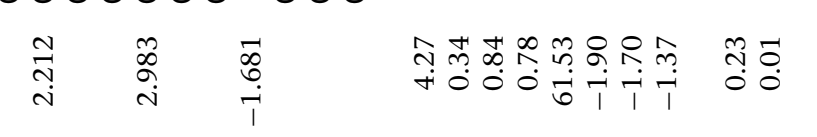

$$
\begin{aligned}
& \begin{array}{ccc}
\vec{N} & \overrightarrow{0} & \stackrel{m}{0} \\
\stackrel{0}{0} & \stackrel{0}{0} & \stackrel{0}{i} \\
& 0 & i
\end{array} \\
& \text { I } 1 \\
& \text { 芯 }
\end{aligned}
$$

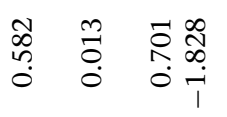

$$
\begin{aligned}
& \text { 王王王 }
\end{aligned}
$$




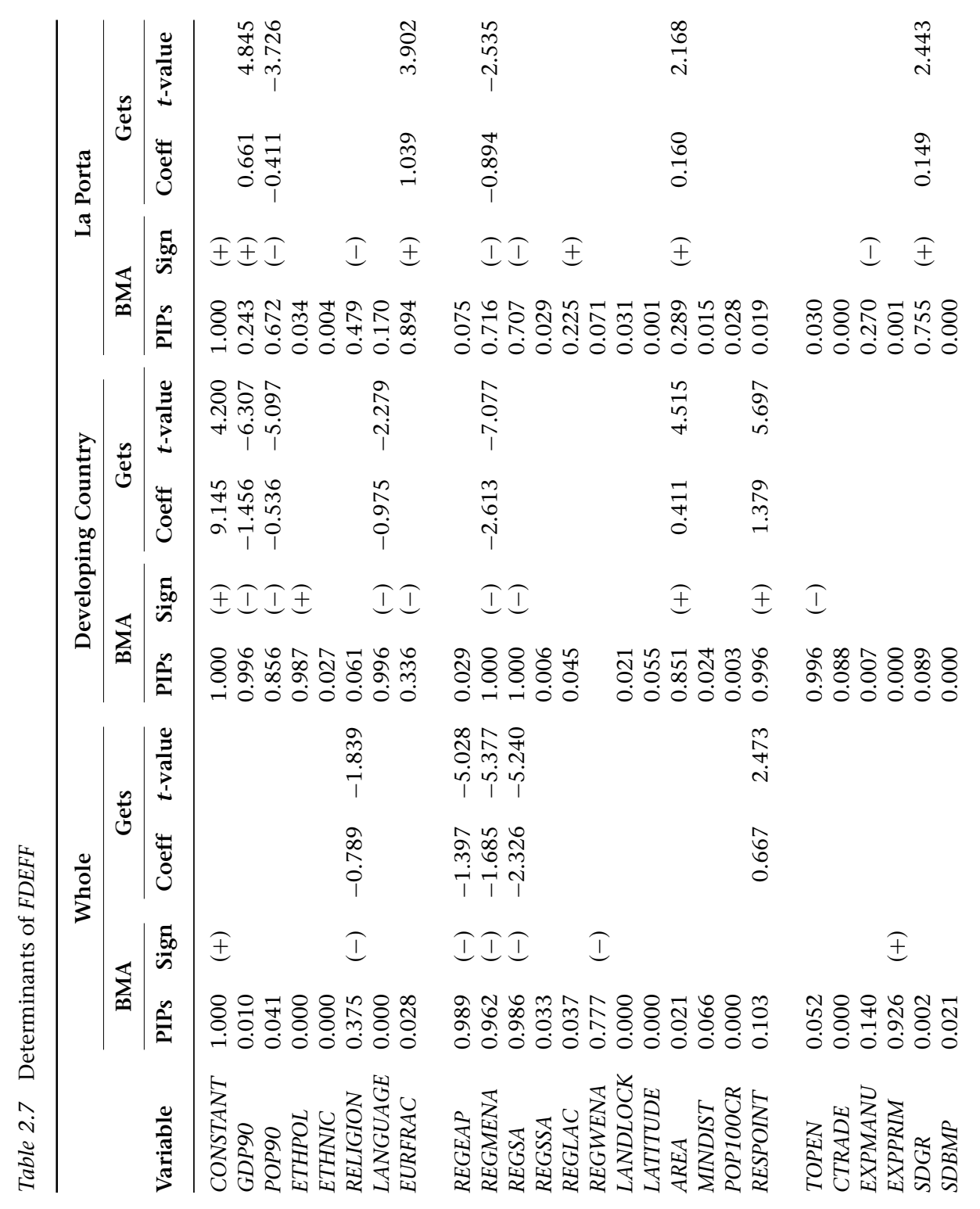




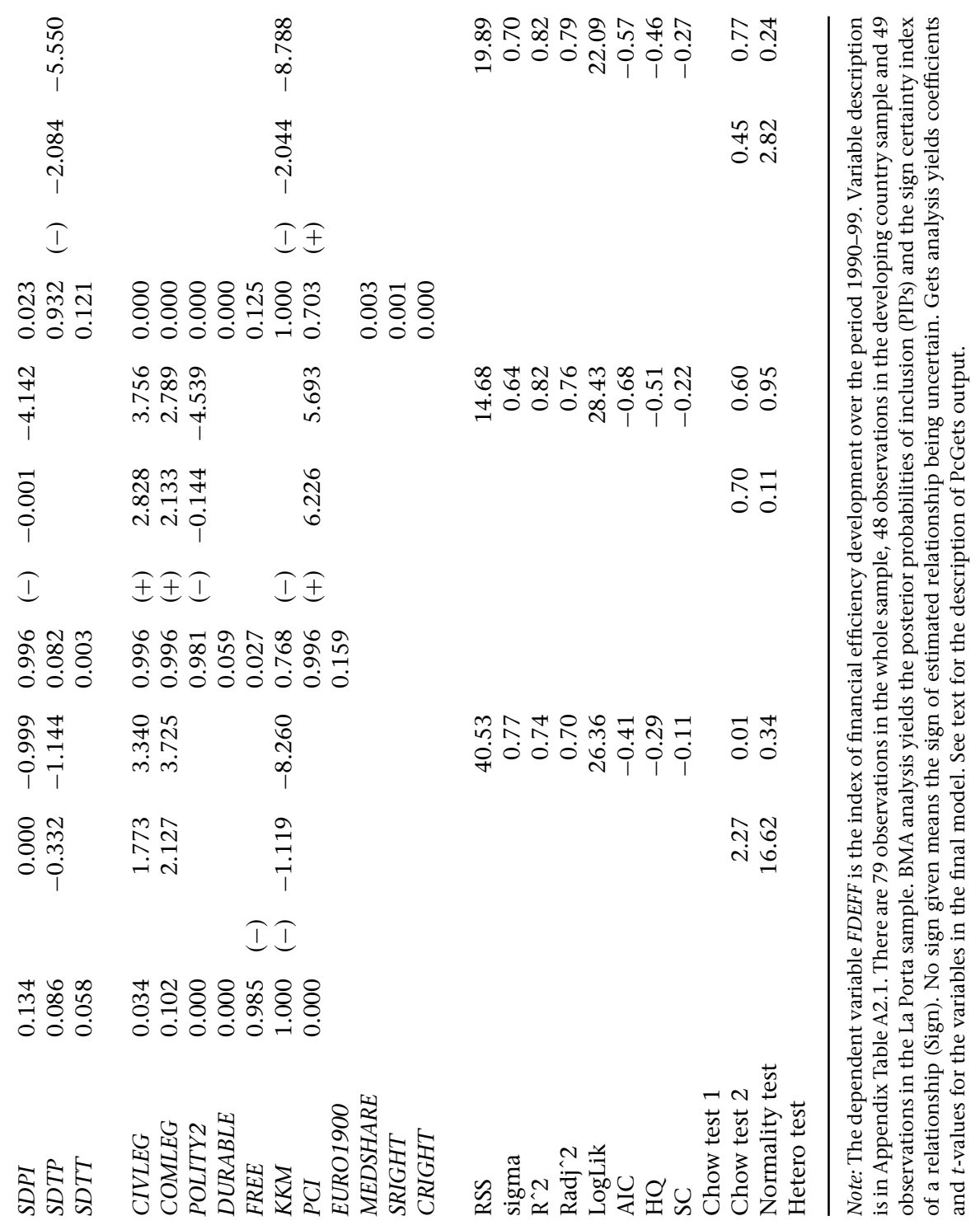




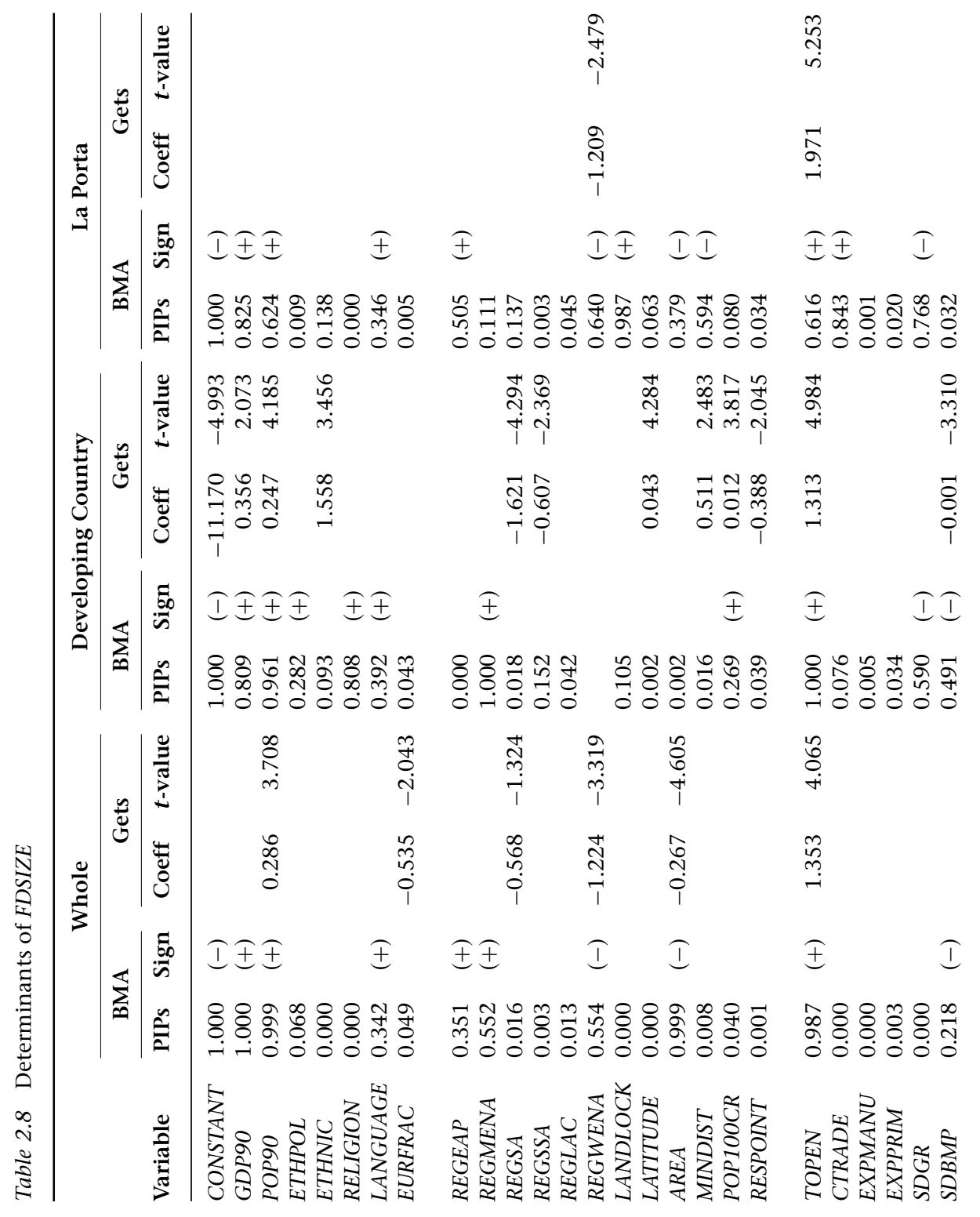




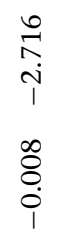

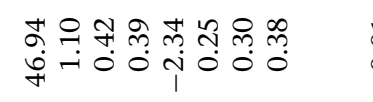

\section{I I}

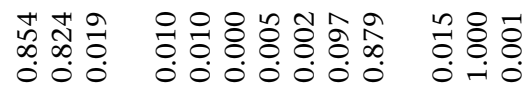

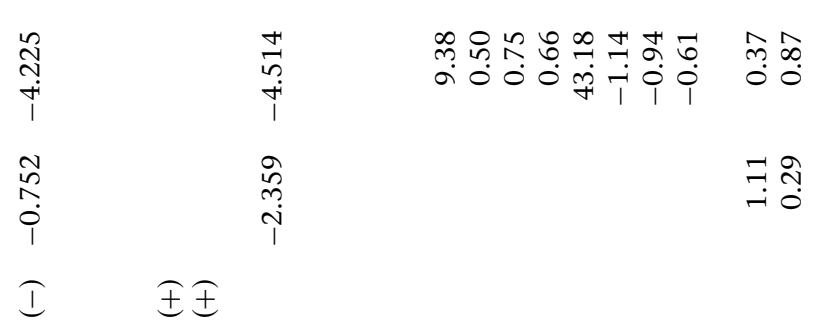

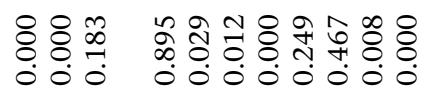

$$
\begin{aligned}
& \text { 옳 } \\
& \text { 害 鳟 }
\end{aligned}
$$

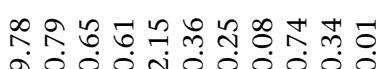

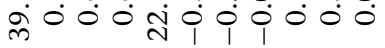

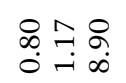$$
\text { I王 I }
$$

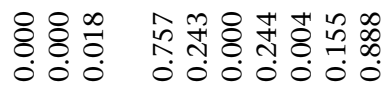

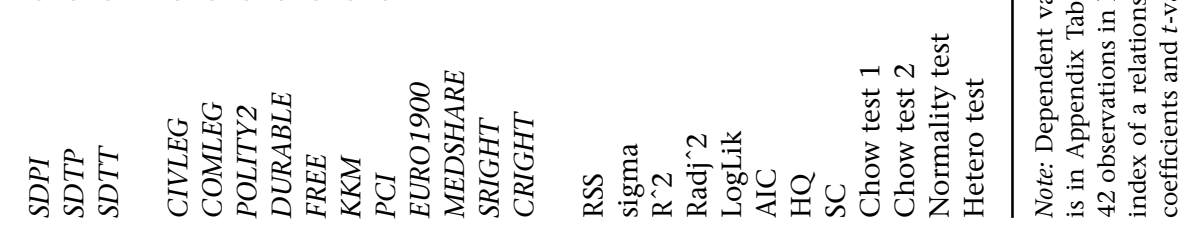


and North African countries tend to have more efficient financial markets. Financial markets are more efficient in countries where institutional quality (captured by $K K M$ ) is higher. The results from two subsamples show that initial GDP and population are also important for FDEFF.

The determinants of financial size development (FDSIZE), also called financial depth, are reported in Table 2.8. The whole sample has 73 observations, the developing country sample has 51 and the La Porta sample has 42. The BMA and Gets analyses on the whole sample suggest that financial depth in a country is positively related to the initial population. The West European and North American countries - including most developed countries - witnessed a decline in financial depth. Countries with a larger land area experience relatively less financial size development. Countries with a more open trade policy are found to have better financial development in terms of size. Financial depth is also associated with a stable political system (captured by DURABLE) and fewer political constraints on the executive (captured by $P C I$ ). Most of these findings are supported by analyses based on the developing country and the La Porta samples. In addition, the analyses from the La Porta sample show that financial depth might be closely related to shareholders' rights.

We now turn to the case of bond market development. Since there are only size measures for bond market development and bond market capitalization available in the World Bank Financial Development and Financial Structure Database (2008) with incomplete data for many developing countries, the above financial development measures do not include indexes of bond market development. Appendix Table A2.8 presents the specific BMA and Gets analyses for bond market development, denoted by FDBOND, which is the sum of the private and public bonds share over GDP in 1990s. The analyses are based on the La Porta sample of 35 countries subject to data availability. The results show that initial GDP level (GDP90), language fractionalization index (LANGUAGE), East Asian and Pacific countries (REGEAP), population proportion in coastal areas ${ }^{25}$ (POP100CR), terms of trade volatility $(S D T T)$ and governance index $(K K M)$ may influence bond market development. The results support previous findings in terms of institutions, policy and geography being important for financial development, but further study critically depends on the availability of additional data.

\subsection{Conclusions}

The analysis jointly applies the BMA and Gets methods to study what drives financial development using 39 institutional, policy and 
geographic variables. The combination of these two methods has the potential for incorporating the merits of each method and minimizing their limits, showing advantages in mitigating arbitrary choices and increasing precision in model selection. To explore the structural causes of financial development, the variables considered here are either predetermined or evolving slowly over time.

Of 39 individual variables, this research finds that the legal origin and institutional quality are significantly associated with financial development, as are the initial income and population. These findings are consistent with the literature.

The finding that the legal origins influence financial development supports the emphasis on the legal determinants of financial development of La Porta et al. (1998), who argued that the origins of the legal code substantially influence the treatment of creditors and shareholders, and the efficiency of contract enforcement. They document that countries with French Civil Law are said to have comparatively inefficient contract enforcement and higher corruption, and less well-developed financial systems, whilst countries with British legal origin achieve higher levels of financial development.

On the role of institutions in financial development, Beck et al. (2003) is a significant work among others. By applying the settler mortality hypothesis of Acemoglu et al. (2001) to financial development, Beck et al. (2003) argue that extractive colonizers in an inhospitable environment aimed to establish institutions that privileged small elite groups rather than private investors, while the settler colonizers in more favourable environments were more likely to create institutions that supported private property rights and balanced the power of the state, therefore favouring financial development.

The importance of income levels for financial development has been addressed in Levine (1997, 2003, 2005). In considering the banking sector development in transition economies, Jaffee and Levonian (2001) demonstrate that the level of GDP per capita and the saving rate have positive effects on the banking system structure as measured by bank assets, numbers, branches and employees for 23 transition economies. On the impact of differences in culture on the process of financial development, Stulz and Williamson (2003) provide evidence that culture, proxied by differences in religion and language, predicts cross-country variation in the protection and enforcement of investor rights, especially for creditor rights.

Taken as a whole, whilst this research shows the significant roles played by institutions, policy and geography, it highlights the dominant role of 
institutions over policy and geography in the process of financial development. The findings on the significant effects of these structural factors, which are relatively time-invariant, tend to suggest that efforts by the government to better institution quality, implement more open trade and sound macroeconomic policies and improve geographic infrastructure can stimulate financial development in the long run. An efficient and transparent institutional and legal system and a free and just society are especially important for the development of financial markets. Further research, as in Abiad and Mody (2005) and Chapter 5, is needed to explore what causes governments to undertake financial reforms aimed at financial development.

\section{Appendix text}

Here is the derivation of the posterior model probability in BMA. ${ }^{26}$ We suppose there are many models, $\left\{M_{1}, \ldots M_{K}\right\}$ for the data $D$. Every model is specified by a vector of $d$ unknown parameters $\theta_{i}=\left(\theta_{i 1}, \theta_{i 2}, \ldots \theta_{i d}\right), i=1,2 \ldots K$. These models may be nested or not. Bayesians treat the unknown parameters as random variables.

Let $\Delta$ denote a quantity of interest such as a parameter. The posterior distribution of $\Delta$ given data $D$ is derived according to

$$
P(\Delta \mid D)=\sum_{i=1}^{K} P\left(\Delta \mid D, M_{k}\right) P\left(M_{k} \mid D\right)
$$

where $P\left(M_{k} \mid D\right)$ are the posterior model probabilities, and $P\left(\Delta \mid D, M_{k}\right)$ is the posterior distribution of $\Delta$ given the data $D$ and model $M_{k}$.

The equation contains all information needed to make inferences about $\Delta$, indicating that the posterior distribution of $\Delta$ given data $D$ is a weighted average of its posterior distributions given data $D$ and a specific model. The weights are the posterior model probabilities, $P\left(M_{k} \mid D\right)$, which can be obtained by Bayes' theorem

$$
P\left(M_{k} \mid D\right)=\frac{P\left(D \mid M_{k}\right) P\left(M_{k}\right)}{\sum_{i=1}^{K} P\left(D \mid M_{i}\right) P\left(M_{i}\right)}
$$

where $P\left(M_{k}\right)$ is the prior probability of model $i(i=1,2 \ldots K)$, and $P\left(D \mid M_{i}\right)$ is the probability of the data given $M_{i}$, also called the integrated (marginal) likelihood for model $M_{i}$ or marginal (predictive) probability of the data given $M_{i}$.

To represent no prior preference for any model, each will start on an equal footing, that is $P\left(M_{1}\right)=P\left(M_{2}\right)=\cdots P\left(M_{K}\right)=\frac{1}{K}$. Therefore the posterior model 
probabilities $P\left(M_{k} \mid D\right)$ can be rewritten as

$$
P\left(M_{k} \mid D\right)=\frac{P\left(D \mid M_{k}\right)}{\sum_{i=1}^{K} P\left(D \mid M_{i}\right)}
$$

To identify the value of $P\left(D \mid M_{k}\right)$, it is useful to compare model $M_{k}$ with a baseline model. A null model $\left(M_{0}\right)$ in which no independent variables are included is usually used as a baseline model. ${ }^{27}$

Let $B_{k 0}$ be the Bayes factor for model $M_{k}$ against model $M_{0}$, that is

$$
B_{k 0}=\frac{P\left(D \mid M_{k}\right)}{P\left(D \mid M_{0}\right)}
$$

then

$$
2 \log B_{k 0}=2 \log P\left(D \mid M_{k}\right)-2 \log P\left(D \mid M_{0}\right)
$$

Using an approach developed by Raftery (1995), twice the log of the Bayesian factor, " $2 \log B_{k 0}$ ", can be expressed as the approximation of the difference between $B I C_{0}$ and $B I C_{k}$, the values of $B I C$ for the null model, $M_{0}$, and model, $M_{k}$, respectively

$$
2 \log B_{k 0} \approx B I C_{0}-B I C_{k}
$$

The fact that $B I C_{0}=0$ yields the approximation for the posterior probability $P\left(D \mid M_{k}\right)$, which is

$$
P\left(D \mid M_{k}\right) \propto \exp \left(-\frac{1}{2} B I C_{k}\right)
$$

The posterior model probabilities $P\left(M_{k} \mid D\right)$ can then be written as

$$
P\left(M_{k} \mid D\right) \approx \frac{\exp \left(-\frac{1}{2} B I C_{k}\right)}{\sum_{i=1}^{K} \exp \left(-\frac{1}{2} B I C_{i}\right)}
$$




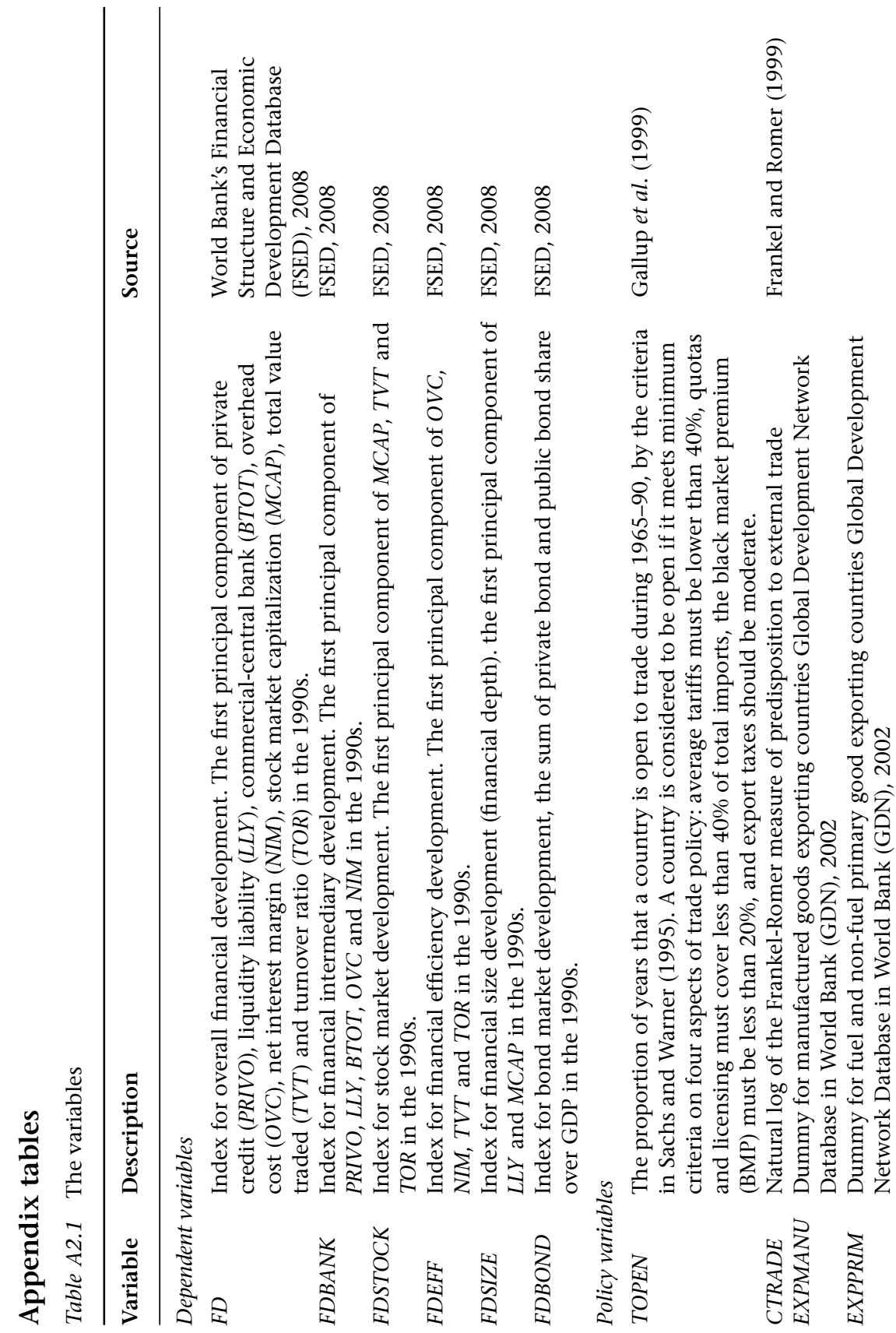




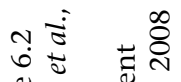

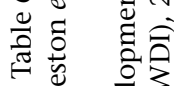

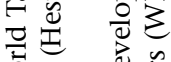 \\ उัช}

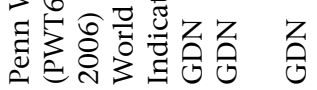

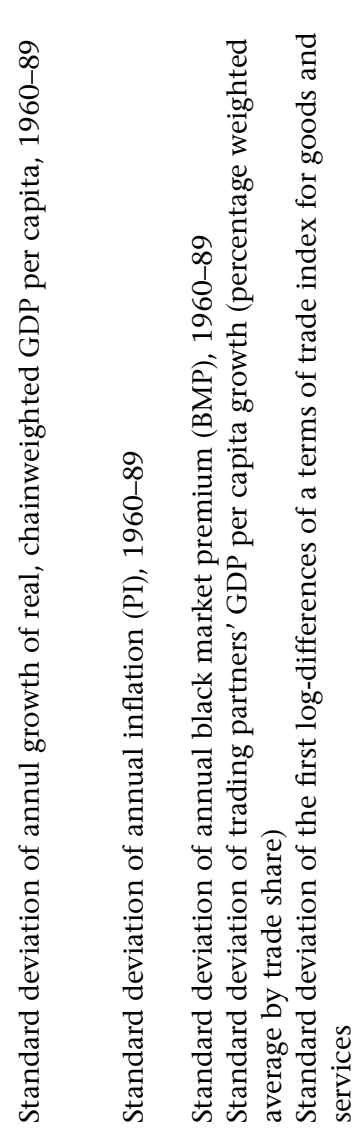

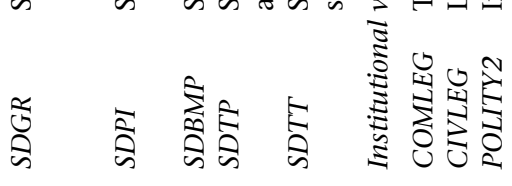

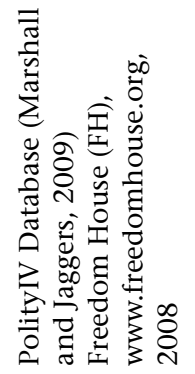

$\underset{\Xi}{\mathbb{E}} \approx$

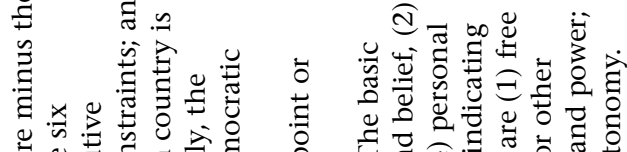

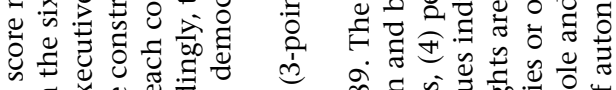
ব)

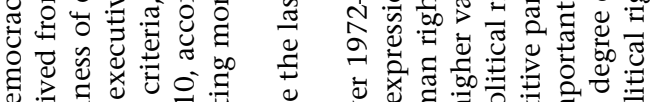

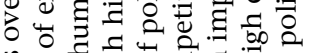

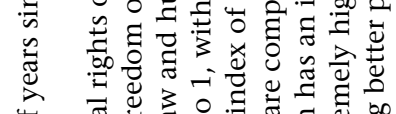
च

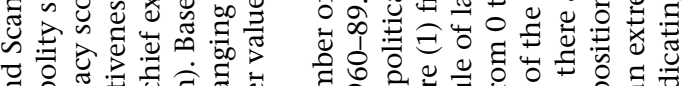

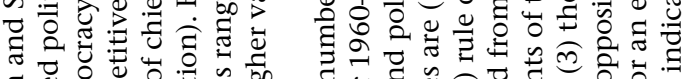

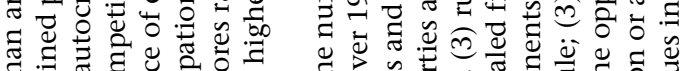

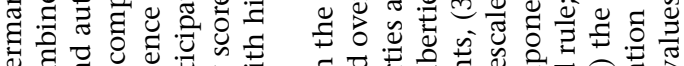

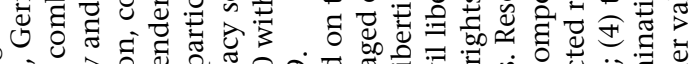

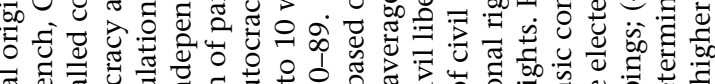

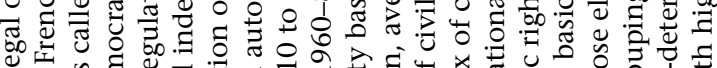

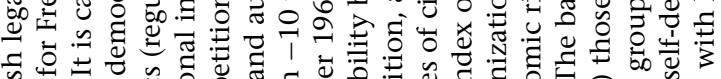

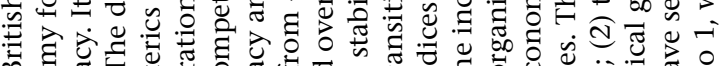

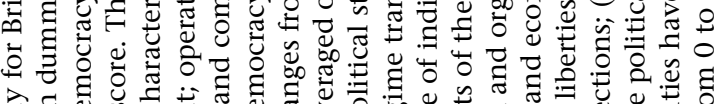

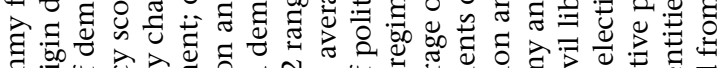

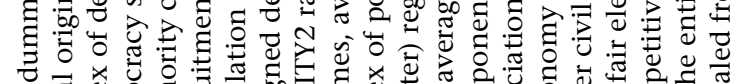

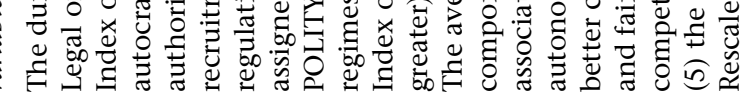




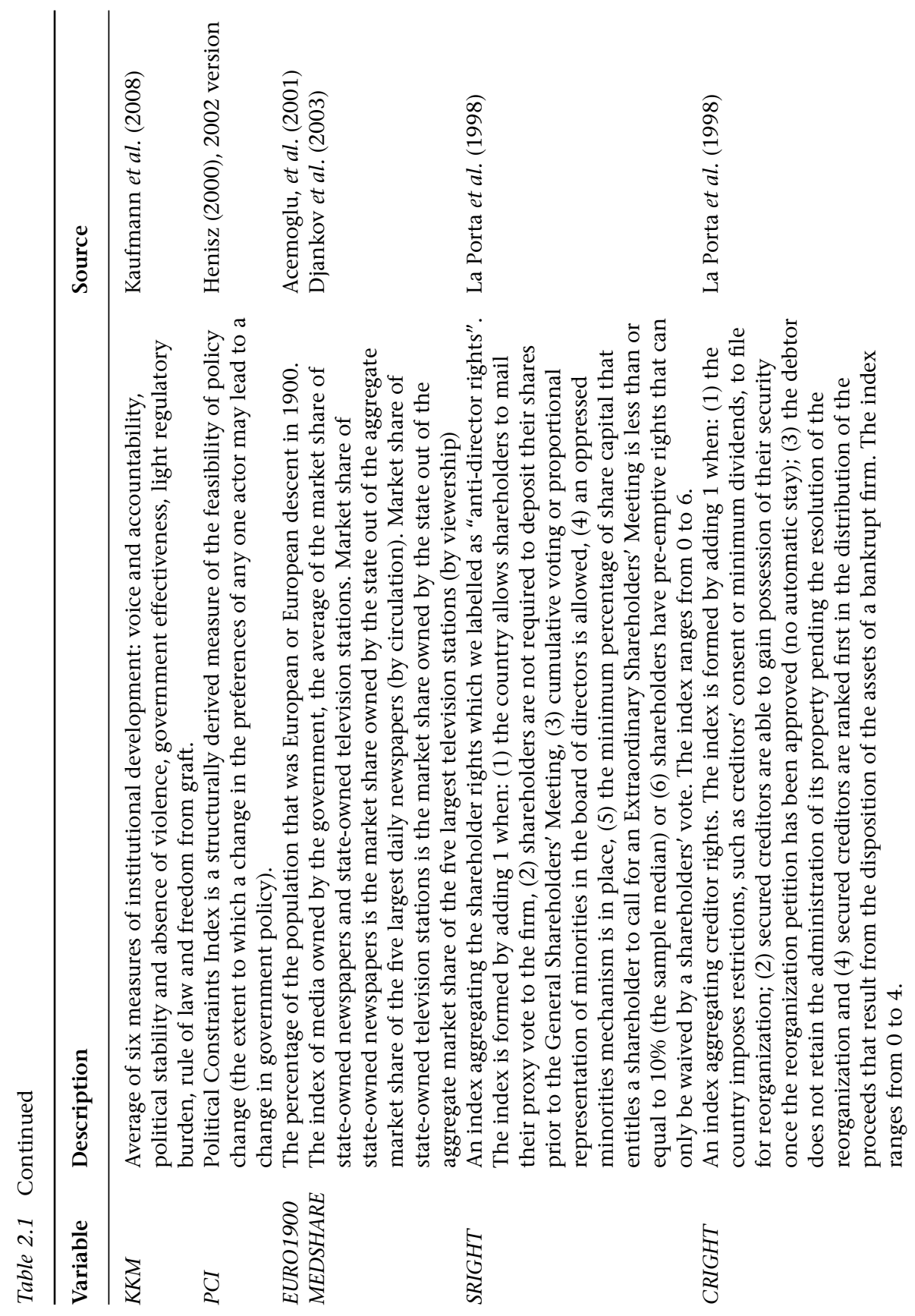



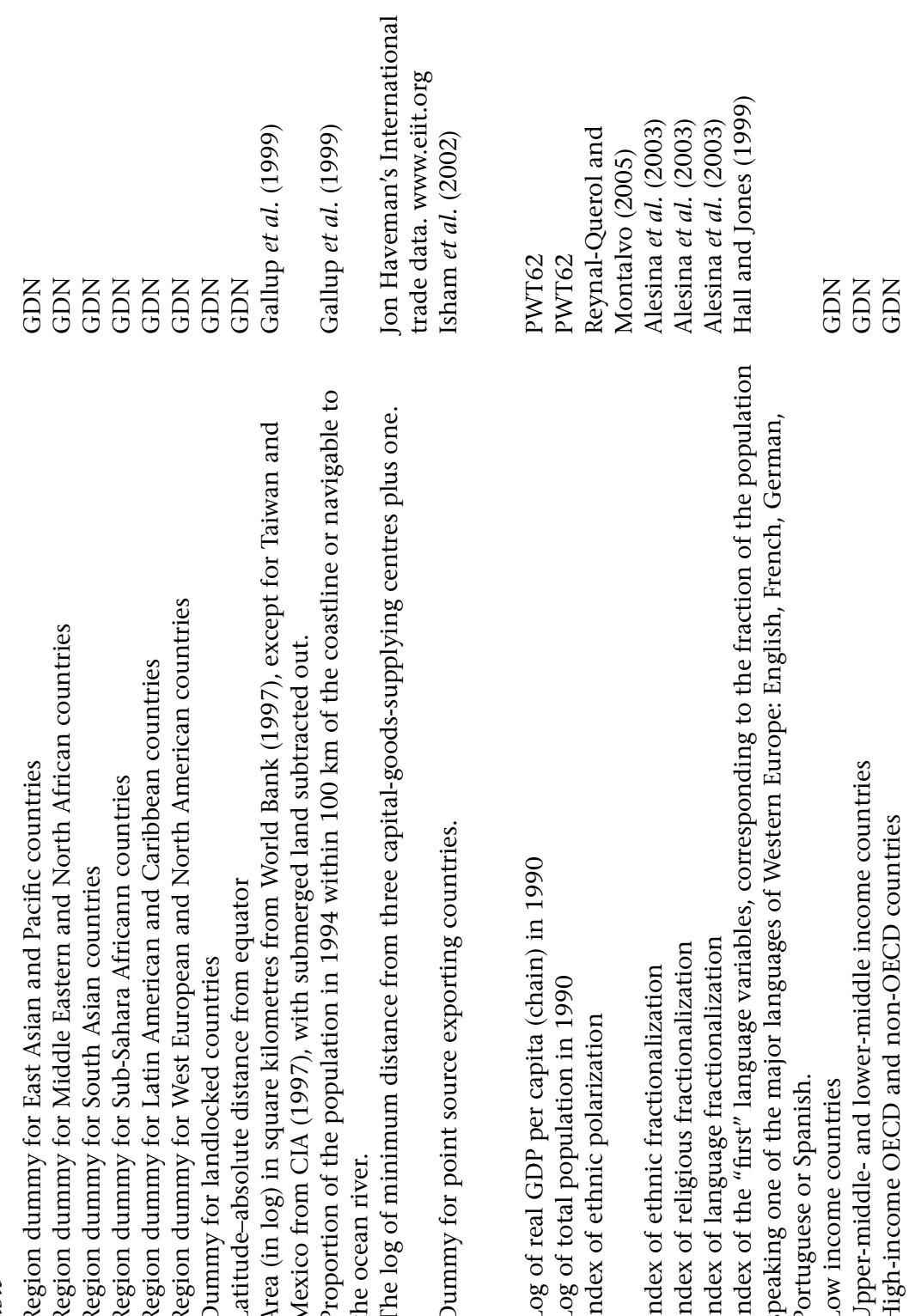
ב

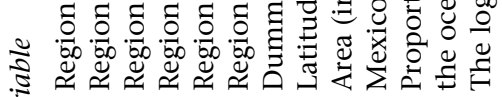

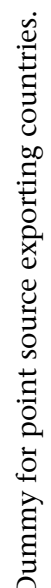

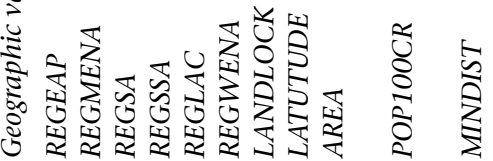

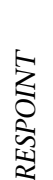

รั

:

总

ำ

पू प⿺辶一

도원

䒿

幽

ㅇํㅁ

:

这

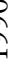

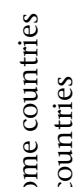

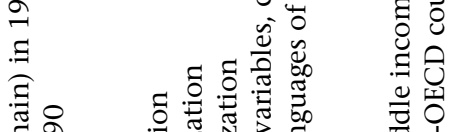

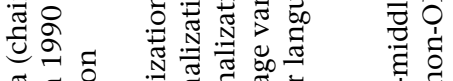

焉营

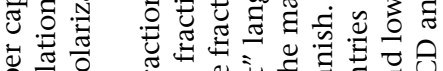

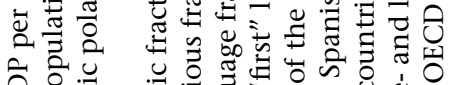

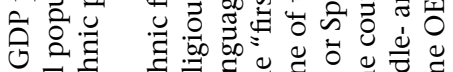

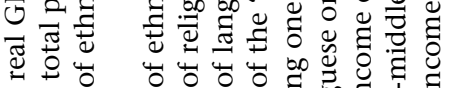

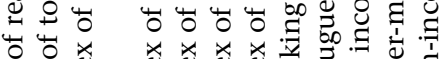

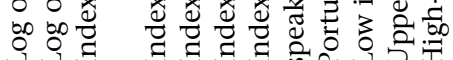
竞 


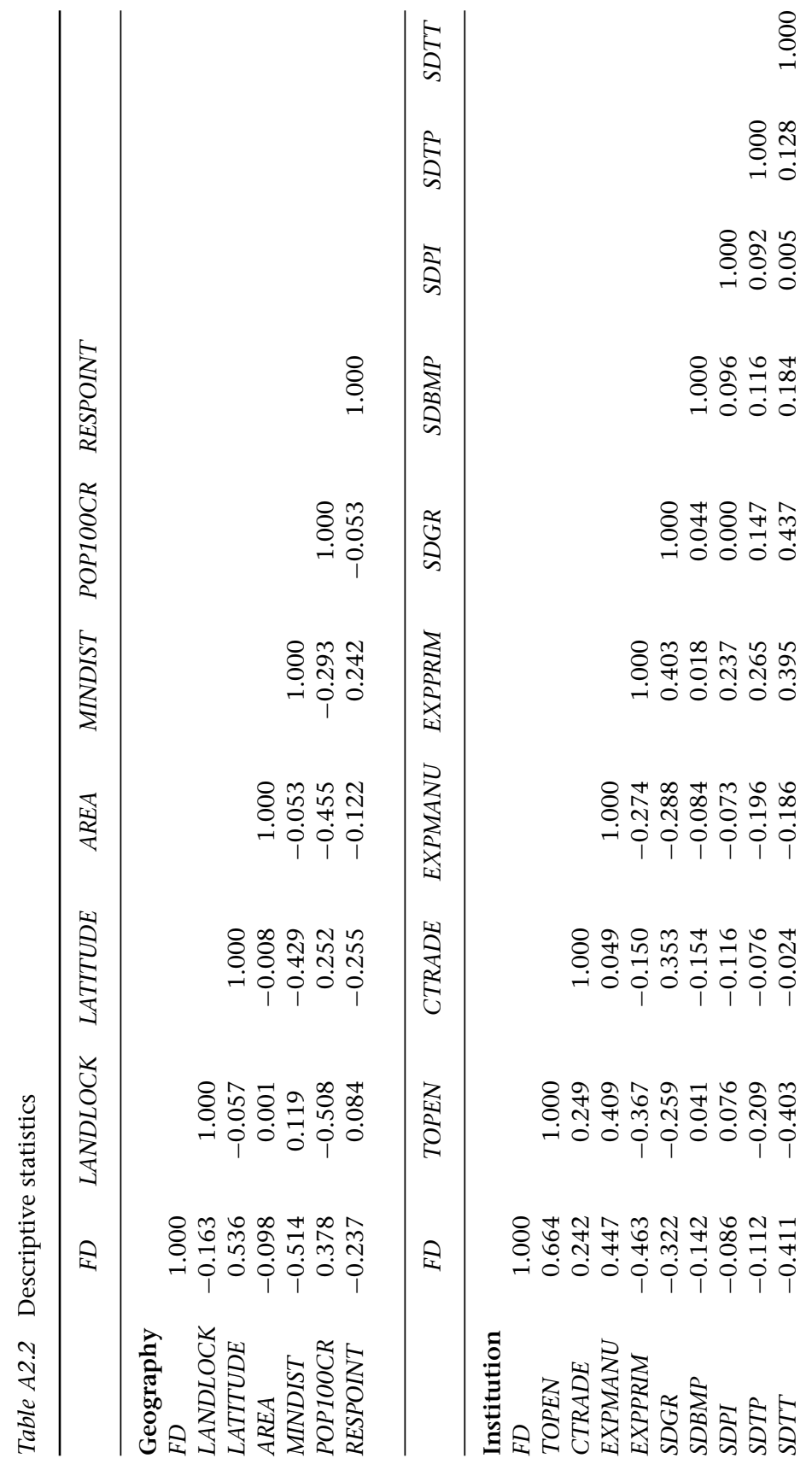




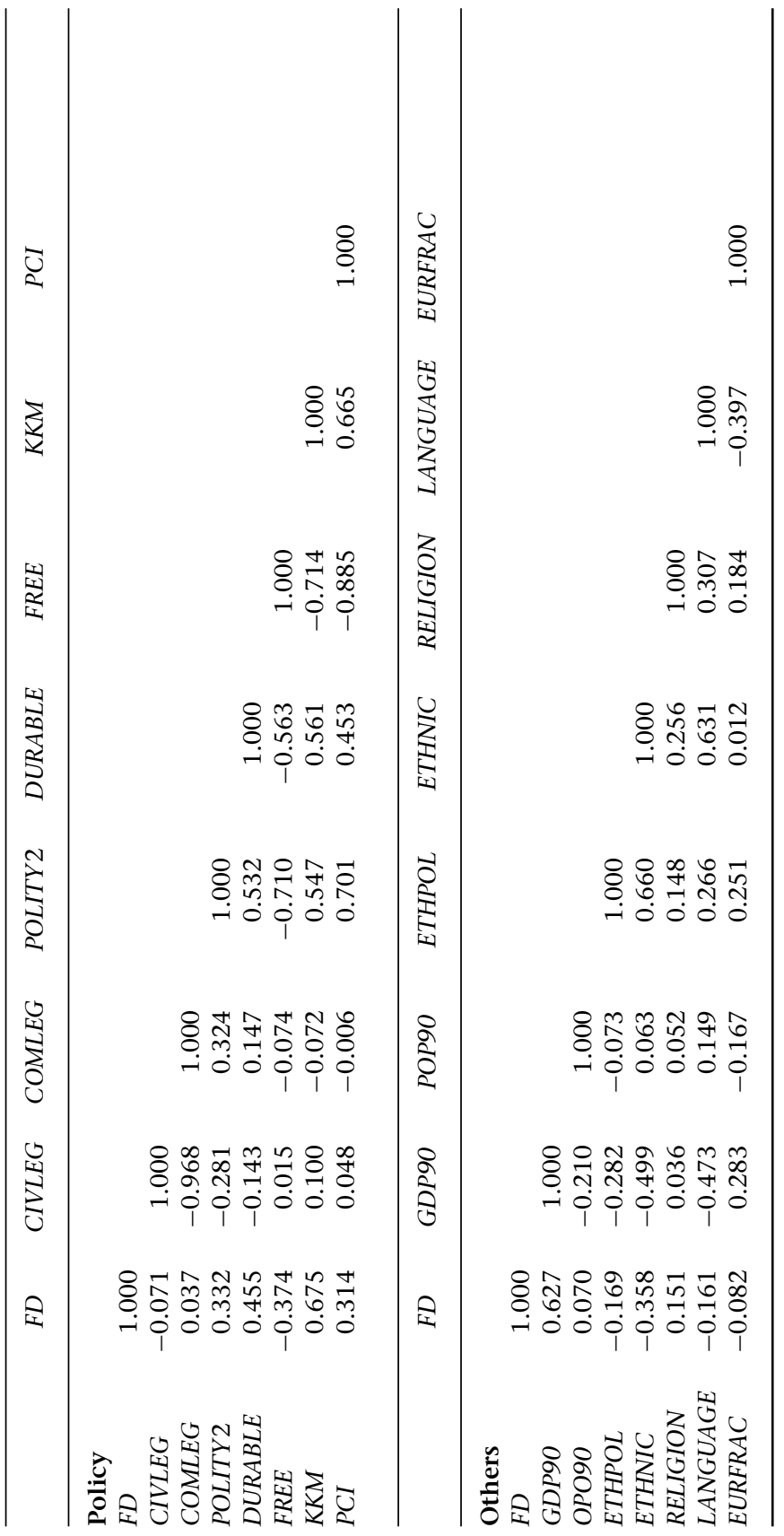


Table A2.3 The list of countries in the full sample

\begin{tabular}{|c|c|c|c|c|c|}
\hline \multicolumn{2}{|c|}{ East Asia \& Pacific } & \multicolumn{2}{|c|}{ Middle East \& } & \multicolumn{2}{|c|}{ South Asia } \\
\hline AUS & Australia & BHR & Bahrain & BGD & Bangladesh \\
\hline $\mathrm{CHN}$ & China & DZA & Algeria & IND & India \\
\hline FJI & Fiji & EGY & Egypt, Arab Rep. & LKA & Sri Lanka \\
\hline HKG & Hong Kong, China & GRC & Greece & NPL & Nepal \\
\hline IDN & Indonesia & IRN & Iran, Islamic Rep. & PAK & Pakistan \\
\hline JPN & Japan & ISR & Israel & & \\
\hline KOR & Korea, Rep. & JOR & Jordan & & \\
\hline MAC & Macao & KWT & Kuwait & & \\
\hline MNG & Mongolia & LBN & Lebanon & & \\
\hline MYS & Malaysia & MAR & Morocco & & \\
\hline NZL & New Zealand & MLT & Malta & & \\
\hline PHL & Philippines & OMN & Oman & & \\
\hline PNG & Papua New Guinea & PRT & Portugal & & \\
\hline SGP & Singapore & QAT & Qatar & & \\
\hline THA & Thailand & SAU & Saudi Arabia & & \\
\hline TWN & Taiwan, China & TUN & Tunisia & & \\
\hline VNM & Vietnam & & & & \\
\hline \multirow{2}{*}{\multicolumn{2}{|c|}{ Sub-Saharan Africa }} & \multirow{2}{*}{\multicolumn{2}{|c|}{$\begin{array}{l}\text { Latin America \& } \\
\text { Caribbean }\end{array}$}} & \multirow{2}{*}{\multicolumn{2}{|c|}{$\begin{array}{l}\text { Western Europe \& } \\
\text { North America }\end{array}$}} \\
\hline & & & & & \\
\hline BDI & Burundi & ARG & Argentina & AUT & Austria \\
\hline BEN & Benin & BOL & Bolivia & BEL & Belgium \\
\hline BFA & Burkina Faso & BRA & Brazil & CAN & Canada \\
\hline BWA & Botswana & BRB & Barbados & CHE & Switzerland \\
\hline CIV & Cote d'Ivoire & CHL & Chile & CYP & Cyprus \\
\hline CMR & Cameroon & COL & Colombia & DEU & Germany \\
\hline ETH & Ethiopia & CRI & Costa Rica & DNK & Denmark \\
\hline GHA & Ghana & DOM & Dominican Rep. & ESP & Spain \\
\hline KEN & Kenya & ECU & Ecuador & FIN & Finland \\
\hline MDG & Madagascar & GTM & Guatemala & FRA & France \\
\hline MLI & Mali & GUY & Guyana & GBR & United Kingdom \\
\hline $\mathrm{MOZ}$ & Mozambique & HND & Honduras & IRL & Ireland \\
\hline MRT & Mauritania & HTI & Haiti & ISL & Iceland \\
\hline MUS & Mauritius & JAM & Jamaica & ITA & Italy \\
\hline MWI & Malawi & MEX & Mexico & LUX & Luxembourg \\
\hline NAM & Namibia & NIC & Nicaragua & NLD & Netherlands \\
\hline NGA & Nigeria & PAN & Panama & NOR & Norway \\
\hline RWA & Rwanda & PER & Peru & SWE & Sweden \\
\hline SDN & Sudan & PRY & Paraguay & USA & United States \\
\hline SEN & Senegal & SLV & El Salvador & & \\
\hline SLE & Sierra Leone & TTO & Trinidad and Tobago & & \\
\hline SWZ & Swaziland & URY & Uruguay & & \\
\hline TGO & Togo & VEN & Venezuela & & \\
\hline UGA & Uganda & & & & \\
\hline ZAF & South Africa & & & & \\
\hline ZMB & Zambia & & & & \\
\hline ZWE & Zimbabwe & & & & \\
\hline
\end{tabular}




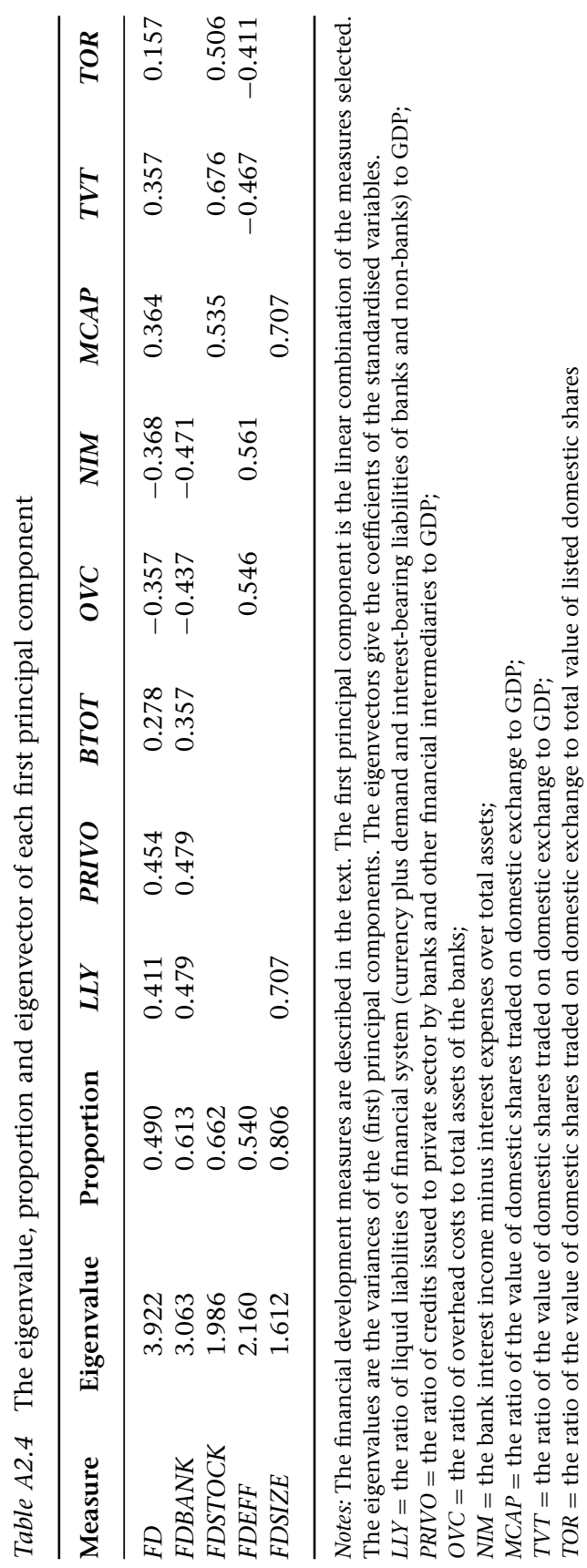




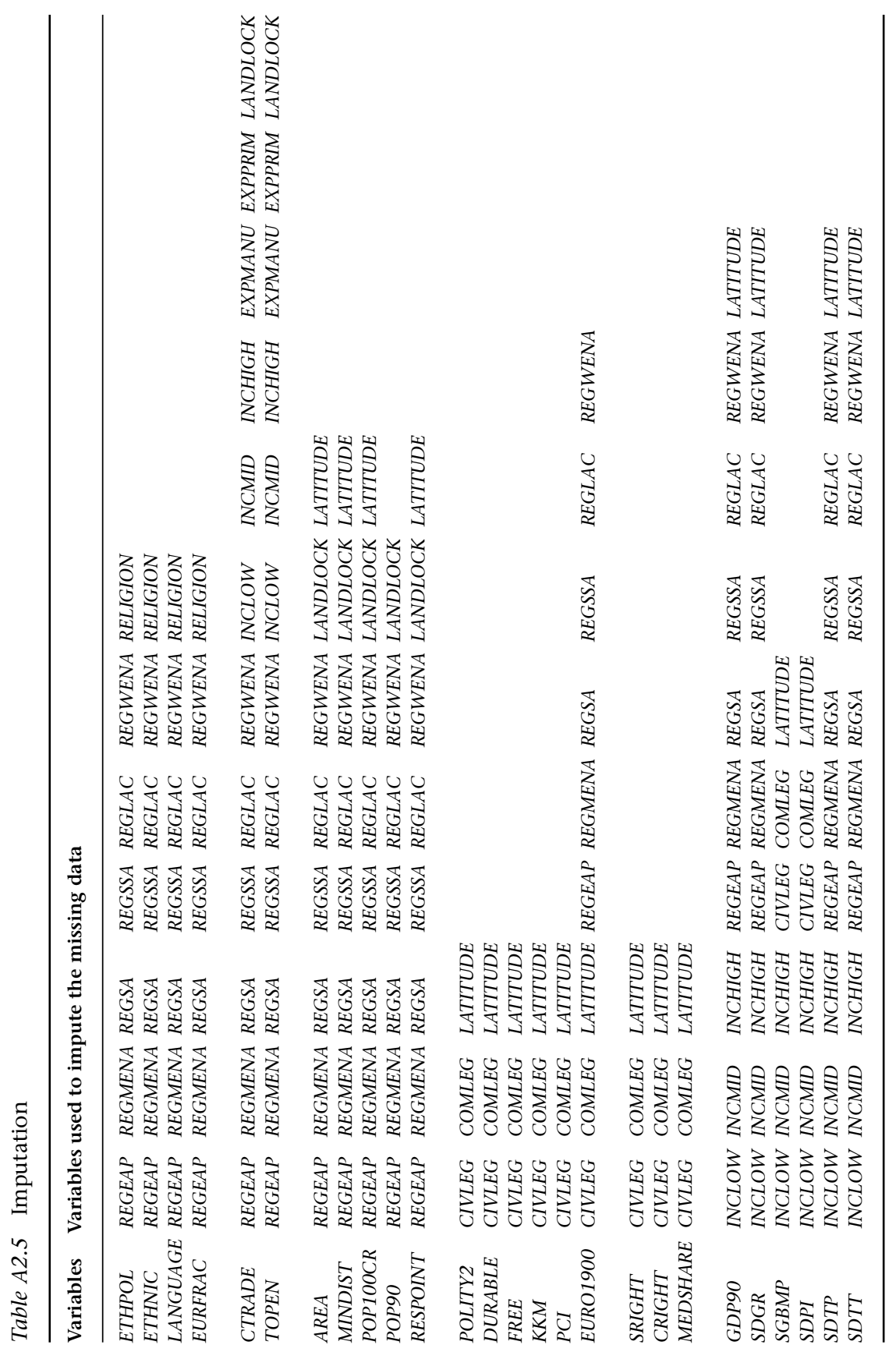


Table A2.6 Setting for PcGets

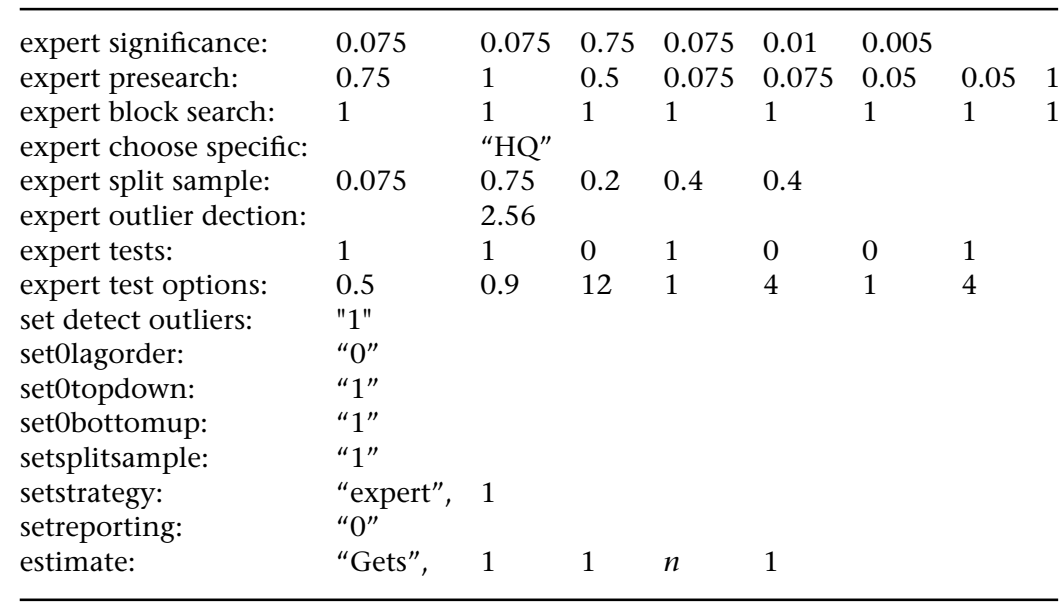

Note: A change has been made to the "liberal strategy" default setting by increasing the F pre-search testing (top-down) at step 1 from 0.75 to 1 . " $n$ " denotes the sample size. 


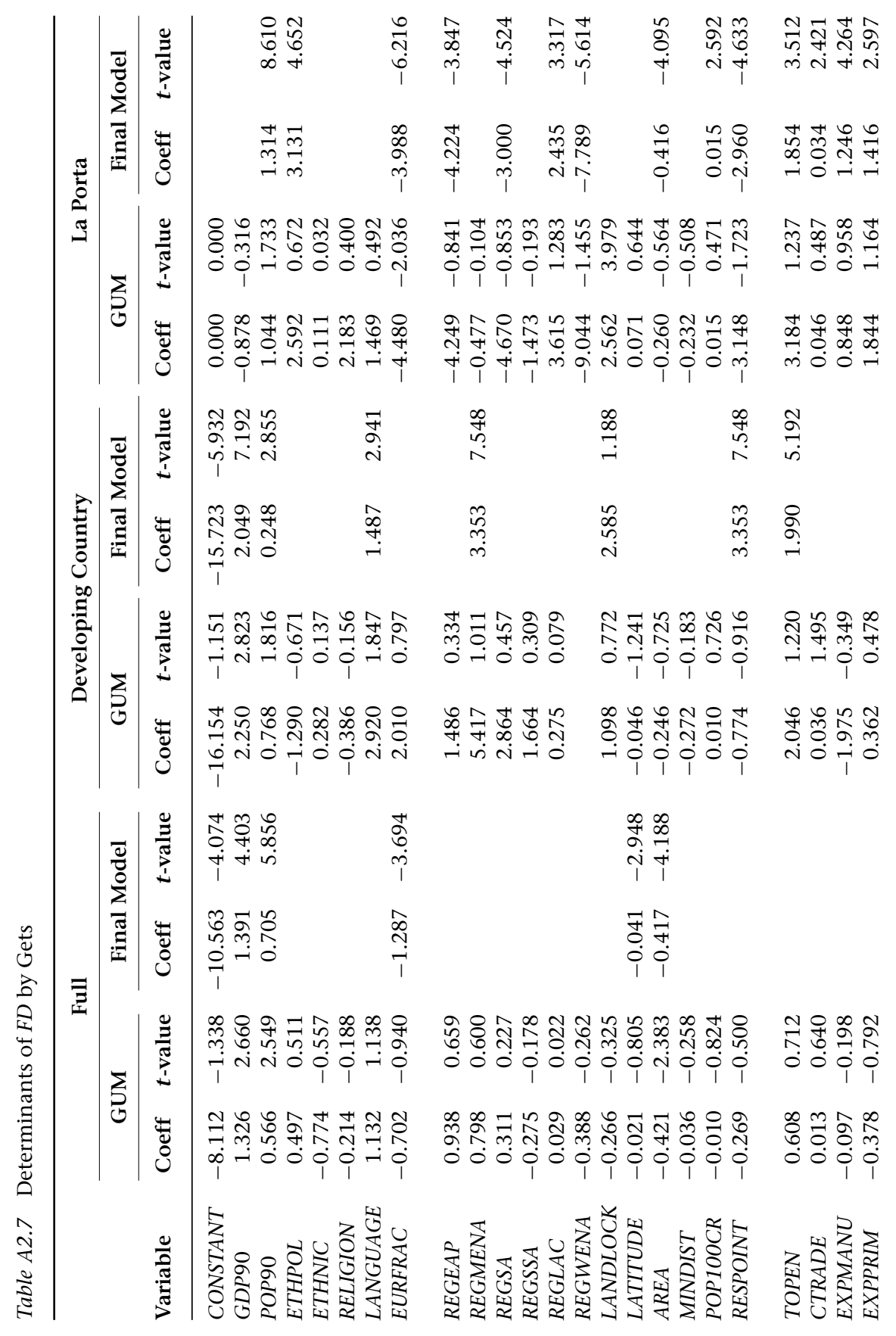




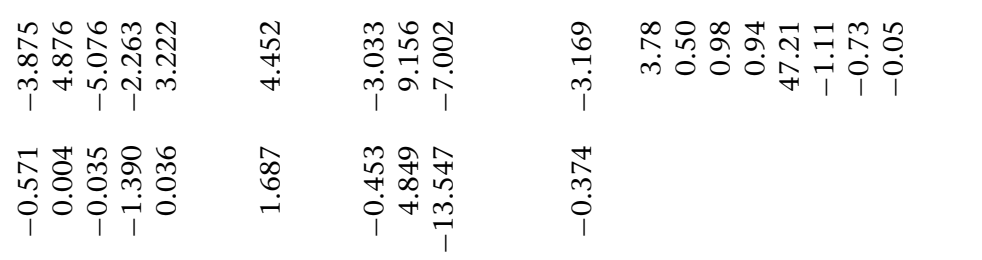

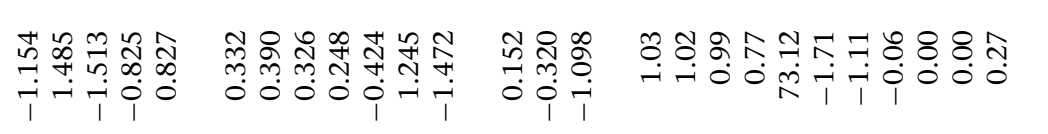

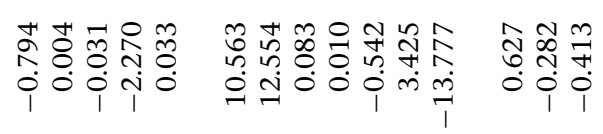

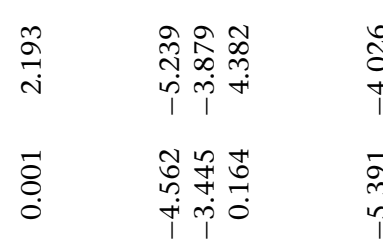

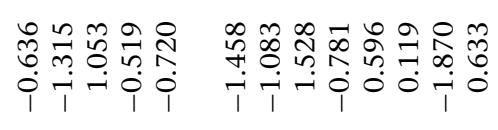

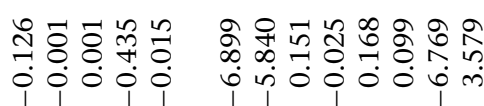

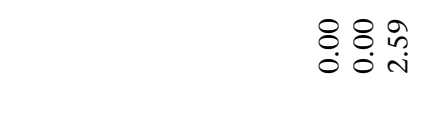

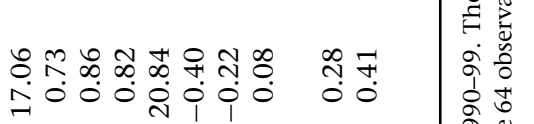

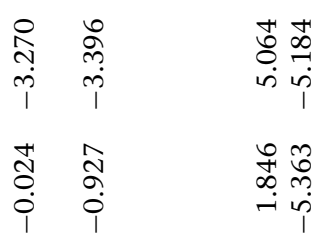

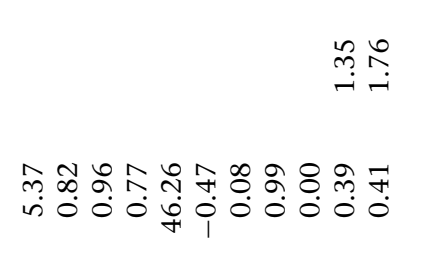

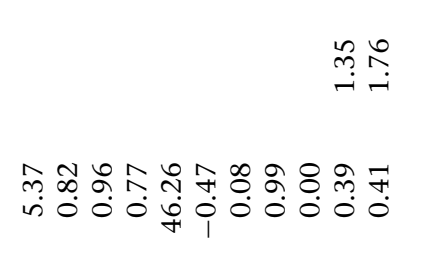

을

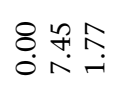

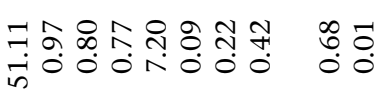

$\stackrel{0}{0} \underset{0}{0}$

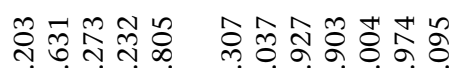

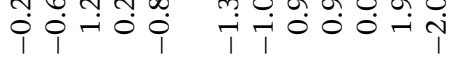

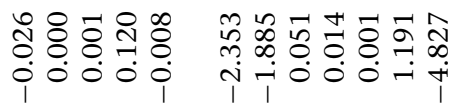

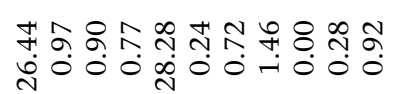

\&̊ำ

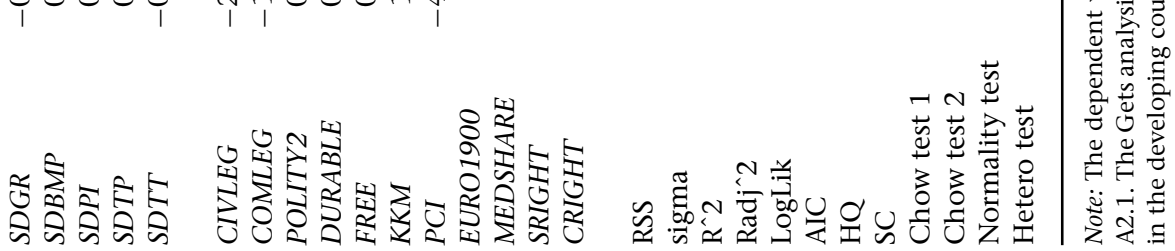


Table A2.8 Determinants of FDBOND

\begin{tabular}{|c|c|c|c|c|}
\hline \multirow[b]{3}{*}{ Variable } & \multicolumn{4}{|c|}{ La Porta Sample } \\
\hline & \multicolumn{2}{|c|}{ BMA } & \multicolumn{2}{|c|}{ Gets } \\
\hline & PIPs & Sign & Coeff & $t$-value \\
\hline CONSTANT & 1.000 & $(-)$ & & \\
\hline GDP90 & 0.105 & & & \\
\hline РОР90 & 0.915 & $(-)$ & & \\
\hline ETHPOL & 0.916 & $(-)$ & & \\
\hline ETHNIC & 0.951 & $(-)$ & & \\
\hline RELIGION & 0.251 & & & \\
\hline$L A N G U A G E$ & 0.979 & $(+)$ & & \\
\hline EURFRAC & 0.920 & $(+)$ & & \\
\hline REGEAP & 0.859 & $(+)$ & & \\
\hline REGMENA & 0.829 & $(+)$ & & \\
\hline REGSA & 0.908 & $(-)$ & & \\
\hline REGSSA & 0.317 & $(-)$ & & \\
\hline REGLAC & 0.874 & $(+)$ & & \\
\hline REGWENA & 0.828 & $(+)$ & & \\
\hline LANDLOCK & 0.842 & $(-)$ & & \\
\hline LATITUDE & 0.084 & & & \\
\hline$A R E A$ & 0.731 & $(-)$ & & \\
\hline MINDIST & 0.233 & & & \\
\hline POP100CR & 0.326 & $(+)$ & & \\
\hline RESPOINT & 0.606 & $(+)$ & & \\
\hline TOPEN & 0.142 & & & \\
\hline CTRADE & 0.848 & $(-)$ & 0.0164 & 3.812 \\
\hline EXPMANU & 0.944 & $(-)$ & & \\
\hline EXPPRIM & 0.938 & $(-)$ & & \\
\hline$S D G R$ & 0.956 & $(+)$ & & \\
\hline$S D B M P$ & 0.173 & & & \\
\hline SDPI & 0.847 & $(+)$ & & \\
\hline SDTP & 0.153 & & & \\
\hline SDTT & 0.311 & & & \\
\hline CIVLEG & 0.465 & $(+)$ & & \\
\hline COMLEG & 0.449 & $(-)$ & & \\
\hline POLITY2 & 0.944 & $(+)$ & & \\
\hline DURABLE & 0.877 & $(+)$ & & \\
\hline FREE & 0.124 & & & \\
\hline$K K M$ & 0.825 & $(-)$ & & \\
\hline$P C I$ & 0.850 & $(+)$ & & \\
\hline \multicolumn{5}{|l|}{ EURO1900 } \\
\hline MEDSHARE & 0.267 & & & \\
\hline SRIGHT & 0.197 & & 0.0751 & 2.717 \\
\hline CRIGHT & 0.838 & $(+)$ & & \\
\hline
\end{tabular}


Table A2.8 Continued

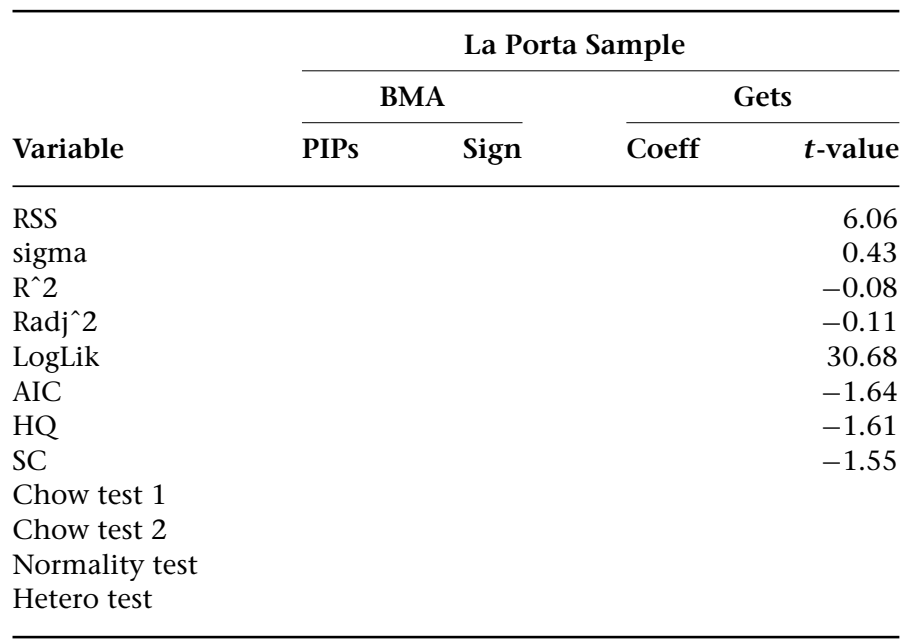

Note: The dependent variable FDBOND is the index of bond market development over the period 1990-99. The variable description is in Appendix Table A2.1. This study is based on La Porta sample with 35 countries. The BMA analysis yields posterior probabilities of inclusion (PIPs), the total posterior model probabilities (PMPs) for all models including a given variable, and the sign certainty index of a relationship (Sign). No sign given means the sign of estimated relationship being uncertain. The Gets analysis yields coefficients and $t$-values for the variables in the final model. 